San Jose State University

SJSU ScholarWorks

Master's Theses

Master's Theses and Graduate Research

2004

\title{
Effects of doping on release stiction for polysilicon MEMS applications
}

Daniel Vroom

San Jose State University

Follow this and additional works at: https://scholarworks.sjsu.edu/etd_theses

\section{Recommended Citation}

Vroom, Daniel, "Effects of doping on release stiction for polysilicon MEMS applications" (2004). Master's Theses. 2689.

DOI: https://doi.org/10.31979/etd.puq8-ygme

https://scholarworks.sjsu.edu/etd_theses/2689

This Thesis is brought to you for free and open access by the Master's Theses and Graduate Research at SJSU ScholarWorks. It has been accepted for inclusion in Master's Theses by an authorized administrator of SJSU ScholarWorks. For more information, please contact scholarworks@sjsu.edu. 
EFFECTS OF DOPING

ON RELEASE STICTION

\section{FOR POLYSILICON MEMS APPLICATIONS}

A Thesis Presented to The Faculty of the Department of Chemical And Materials Engineering

San Jose State University

In Partial Fulfillment Of the Requirements for the Degree Master of Science

by Daniel Vroom

December 2004 
UMI Number: 1425491

\section{INFORMATION TO USERS}

The quality of this reproduction is dependent upon the quality of the copy submitted. Broken or indistinct print, colored or poor quality illustrations and photographs, print bleed-through, substandard margins, and improper alignment can adversely affect reproduction.

In the unlikely event that the author did not send a complete manuscript and there are missing pages, these will be noted. Also, if unauthorized copyright material had to be removed, a note will indicate the deletion.

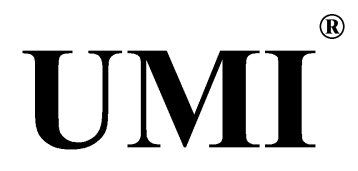

UMI Microform 1425491

Copyright 2005 by ProQuest Information and Learning Company.

All rights reserved. This microform edition is protected against unauthorized copying under Title 17, United States Code.

ProQuest Information and Learning Company 300 North Zeeb Road

P.O. Box 1346

Ann Arbor, MI 48106-1346 
c 2004

Daniel Vroom

ALL RIGHTS RESERVED 
APPROVED FOR THE DEPARTMENT OF CHEMICAL AND MATERIALS ENGINEERING

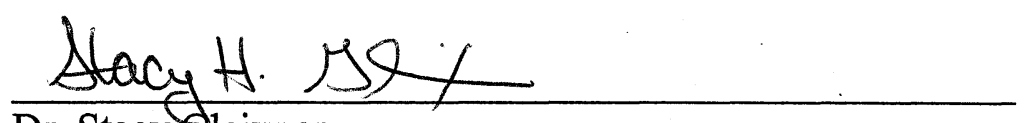

Dr. Stacy Gleixner

$\frac{\text { Gina Selvaduray }}{\text { Dr. Gun Selvaduray }}$

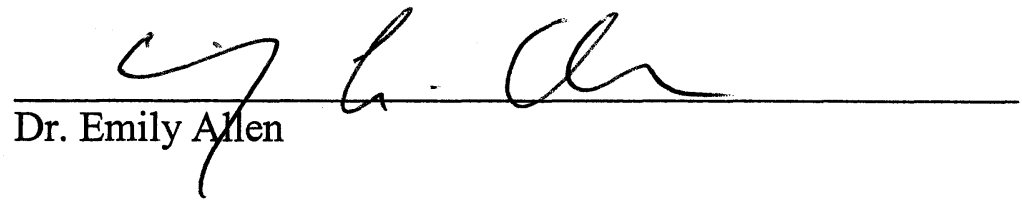

APPROVED FOR THE UNIVERSITY

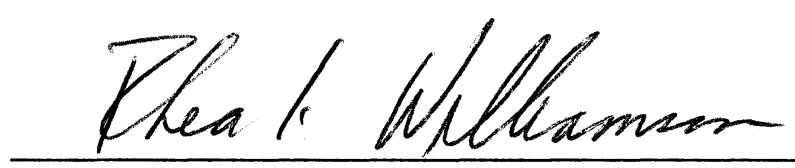




\section{ABSTRACT \\ EFFECTS OF DOPING \\ ON RELEASE STICTION \\ FOR POLYSILICON MEMS APPLICATIONS}

\section{by Daniel Vroom}

The effects of doping the bottom and structural polysilicon layers for MEMS cantilever beam structures with respect to release stiction has been investigated. Test structures consisting of beams ranging in length from 60 to 400 microns were doped with either phosphorus or boron at two extreme concentrations, as well as un-doped control wafers, and analyzed via optical interferometry for release stiction. Results indicate large differences in release stiction with the highly doped phosphorus samples exhibiting more than a fifteen fold increase in release stiction compared to boron and control samples. The main effect of highly doped phosphorus samples appears to be in changing the surface from hydrophobic to hydrophilic, allowing more water to remain on the surface, greatly increasing release stiction. Results indicate no difference between doping the bottom poly silicon layer or the top structural layer, with both showing large degrees of release stiction. Results also show a drying time effect, with the number of stuck beams decreasing between subsequent measurements. 


\section{ACKNOWLEDGEMENTS}

The author would like to thank Dr. Stacy Gleixner of the Chemical and Materials Engineering Department of San Jose State University for her guidance and assistance throughout the research, data analysis, and manuscript preparation associated with this project. Additionally, the author would like to acknowledge the contributions of his reading committee members, Dr. Guna Selvaduray and Dr. Emily Allen, both of the Chemical and Materials Engineering Department of San Jose State University.

The author would like to acknowledge Kevin Hermosillo for assisting with the beam mask layout, the beam mask $\mathrm{CAD}$, and for assistance on the process development for beam fabrication, and also Jenny Suwanmethanond for her assistance with SEM analysis of the beam structures.

And the author would also like to acknowledge the Stanford Nanofabrication Facility and their New User's Grant, as well as the California State University Research Grant. 


\section{TABLE OF CONTENTS}

ABSTRACT

Page

iv

ACKNOWLEDGMENTS $\mathrm{v}$

LIST OF TABLES vii

LIST OF FIGURES viii

CHAPTER 1. INTRODUCTION 1

CHAPTER 2. LITERATURE REVIEW 8

2.1 Introduction $\quad 8$

2.2 Effects of Doping on Surface Properties 9

2.3 Stiction Effects for Cantilever Beams 21

$\begin{array}{ll}\text { CHAPTER 3. EXPERIMENTAL } & 24\end{array}$

3.1 Research Objective $\quad 24$

3.2 Research Approach-Wafer Processing 25

3.3 Stiction Analysis 31

CHAPTER 4. RESULTS 34

4.1 Results: Device Fabrication 34

4.1.1 Polysilicon Film Stress Relief $\quad 34$

4.1.2 Film Thickness Effects 36

4.1.3 Doping Levels and Dopant Profiles 38

4.2 Results: Release Stiction Analysis 42

4.2.1 Surface Layer Doping Effects 42 
4.2.2 Surface Layer Doping: Effects of Beam Size on Stiction

4.2.3 Surface Layer Doping: Shape of Adhered

Beam

4.2.4 Structural Poly Layer Doping

4.2.5 Analysis of Results

CHAPTER 5. CONCLUSIONS

64

REFERENCES

66

APPENDIX Equipment Operating Conditions

68 


\section{LIST OF TABLES}

Table 1. Annealing Process and Stress Gradients 20

Table 2. Wafer Doping Matrix 28

Table 3. Results of ANOVA Calculations For Oxide Thickness 38

Table 4. Projected Range, $R_{p}$, and Projected Straggle, $\Delta R_{p}$

Table 5. Surface Concentrations for Implanted Wafers 41

Table 6. ANOVA Results for Replicate Groups: All Conditions 46

Table 7. Proportions of Stuck Beams for Chi-squared Proportion 47

Test: $1^{\text {st }}$ Group

Table 8. Proportions of Stuck Beams for Chi-squared Proportion 48 Test: 2ndGroup

Table 9. Beam Base/End Height Difference vs. Number of Stuck 58 Beams 


\section{LIST OF FIGURES}

Figure 1. MEMS comb-drive actuated micro-mirror 2

Figure 2. U.S. Market trend for MEMS during the 1990's 4

Figure 3. Illustration of stiction in MEMS devices 5

Figure 4. Surface roughness as a function of sample type 10

Figure 5. Grain size as a function of sample type 11

Figure 6. Stress as a function of annealing temperature 13

Figure 7. Stress as a function of implant dose and annealing for boron 15

Figure 8. Stress as a function of implant dose and annealing for $\quad 15$ phosphorus

Figure 9. Stress as a function diffusion time for phosphorus 18

Figure 10. Stress gradient for phosphorus doped samples 19

Figure 11. Flow diagram for beam fabrication process 27

Figure 12. Side view of released beam structure 31

Figure 13. Top view of released beam structure 31

Figure 14. Beam layout for stiction analysis 32

Figure 15. Individual beam group (die) for stiction analysis 33

Figure 16. Structural layer polysilicon film stress as a function 34 of anneal

Figure 17. SEM of low stress beams: 150 minute $1000^{\circ} \mathrm{C}$ anneal

Figure 18. Beam base and end height data 36

Figure 19. Average thickness of sacrificial oxide layer 37 
Figure 20. Surface concentration as a function of anneal $\left(1000^{\circ} \mathrm{C}\right)$ for high dose implant

Figure 21. Stiction results for first group of wafers 43

Figure 22. Stiction results for replicate group of wafers 44

Figure 23. Frequency of stuck beams as a function of length 51

Figure 24. Interferometer image of arc shaped adhered beam 52

Figure 25. SEM of arc shaped adhered beam 53

Figure 26. Interferometer image of " $S$ " shaped adhered beam 53

Figure 27. Average lengths of "S" and arc shaped beams 55

Figure 28. Results for top poly layer doping 56

Figure 29. Comparison of top poly layer doping and no top layer 57 doping 


\section{CHAPTER 1}

\section{INTRODUCTION}

Advances in planar processing technology of the semiconductor industry have allowed it to mass-produce integrated circuits at progressively lower costs as the technology has advanced. This has been accomplished by the processing of silicon wafers that contain hundreds of identical chips, each of which may contain millions of individual transistors. This miniaturization of the transistor has allowed the production of smaller microprocessors, with each new generation operating at increasingly faster speeds and at lower costs. One of the by-products of this manufacturing technology has been the advent of microelectrical mechanical systems, or MEMS. The ability to mass produce MEMS devices on silicon substrates with the same processing techniques and tools perfected in the semiconductor industry has the potential to allow MEMS to experience the same type of explosive growth as the integrated circuit.

As their name implies, MEMS are miniature machines that typically range in size from one to several hundred microns [1]. Individual components that make up finished devices include gears, springs, hinges, cantilever beams, diaphragms, micro-mirrors, and micro lenses [1]. These types of components when integrated together, can form devices which can be utilized in applications involving sensors, actuators, data storage, displays, micro fluidics, and fiber optics [1,2]. A Typical MEMS device is shown in Figure 1 [3]. This device shows several MEMS components including an out-of-plane hinged structure, gears, beams, and actuators. In this device, the hinged structure can be pushed up to an angle of about 70 degrees, acting in effect as a pop-up mirror for optical 
applications. MEMS devices date to the 1960 's, with the first successful devices being utilized in printer ink jet heads [4]. Micromotor prototype devices were demonstrated by the mid 1980's, and sensors and actuators followed by the early 1990's [4]. A lot of the current research during the early 2000's has centered on the display and optics industry, as well as micro-fluidics [4].

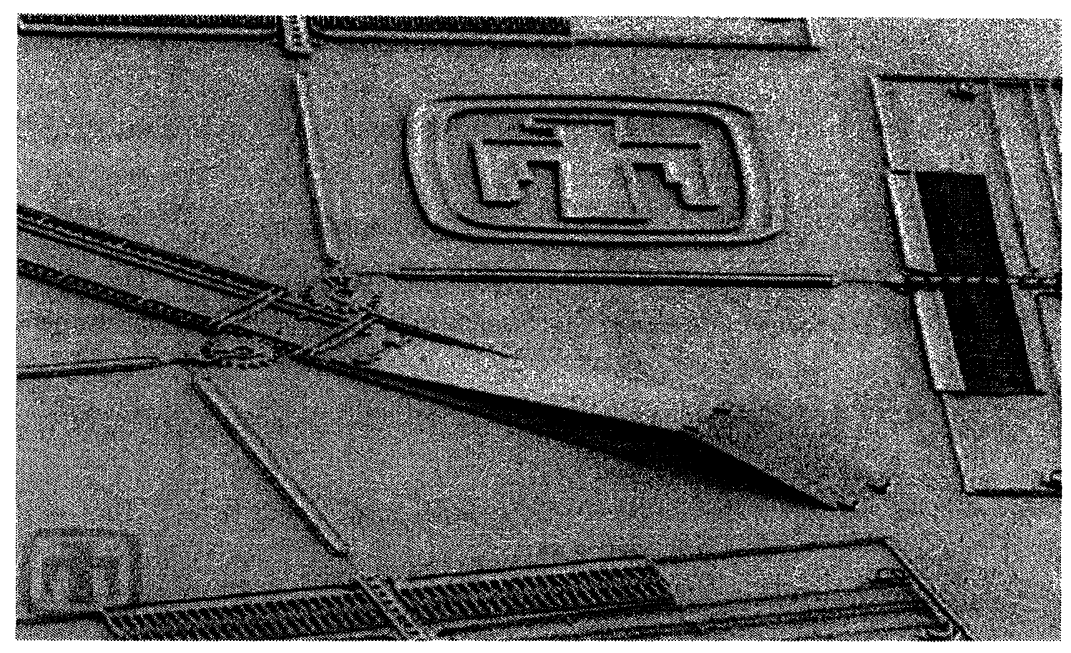

Figure 1. MEMS Comb-Drive Actuated Micro-Mirror [3].

While a lot of prototype devices have been made for numerous applications, commercialization of MEMS devices has lagged behind. The automotive industry has however, successfully commercialized MEMS devices in the form of actuators and sensors for airbags. These devices sense the rapid deceleration characteristic of an accident, at which point they signal the airbag to deploy [1]. In this application the MEMS devices have replaced electro-mechanical devices some 20 times larger than the packaged MEMS device [1], however the main advantage with using MEMS in this 
application is the cost savings. As with many MEMS devices, smaller device sizes have many technical advantages such as smaller footprint and less weight. However, production of multiple devices simultaneously on a single wafer, analogous to IC manufacturing, has lead to significant cost reductions, with a cost reduction factor of about 8 for the airbag sensor application [1]. The market for MEMS as airbag sensors alone is a 2 plus billion dollar industry [5], with this number certain to grow as new automotive applications are developed.

The MEMS industry as a whole has seen better than a ten-fold increase in the total market over the decade of the 1990's [1]. The market trend over this decade is shown in Figure 2, which illustrates that the total market value for the year 2000 was around 14 billion dollars, or about $7 \%$ of the market of the integrated circuit industry from which it heavily borrows its processing technology [1]. This value is expected to increase with the growth of MEMS in fields where it is just beginning to be established, such as fiber optics where its value in this field alone is expected to reach 5 billion dollars annually by 2005 [1]. 


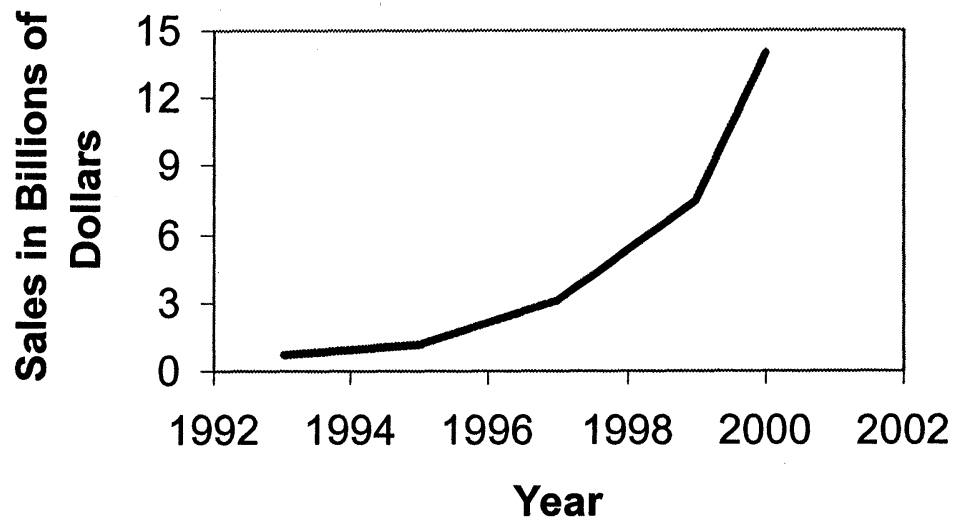

Figure 2. US Market trend for MEMS during the 1990's [2].

The environmental impact of the MEMS industry is similar to that of the semiconductor industry in terms of processing. In fact, MEMS devices can be manufactured in virtually any IC fab with few changes. Issues include the disposal of the wet chemical etchants, solvents, and acids needed for fabrication. The safe use and disposal of toxic gases for dry etching and doping is also a concern in MEMS fabrication. These issues are well understood, as the semiconductor industry has dealt with and continues to deal with them. A second consideration for the environmental impact of MEMS devices concerns their size. MEMS devices are much smaller than the devices they replace, meaning less utilization of natural resources, as well as less waste generated when the device has surpassed its lifetime and is disposed of.

While MEMS technology has the potential to expand into several new fields such as biotechnology and fiber optics, there are significant technical challenges that must be overcome to allow for reliable operation and longevity. One of the most important of 
these challenges is stiction, which is the permanent sticking of movable elements together, preventing normal functioning. Stiction arises from the fact that as MEMS elements shrink in size, the surface energy of the material starts to become significant relative to restoring forces [1]. For example, as the volume of a cantilever beam decreases to some critical value, the energy of the free surfaces can overcome the restoring force of the beam if it were to be deflected during operation [1]. The beam could become permanently stuck to the support, as illustrated in Figure 3.

Stiction can occur at the end of fabrication, which is known as release stiction, or during device operation, which is known as in-use stiction [1]. Release stiction occurs as water (or another liquid) from a post etch rinse dries. Capillary forces can pull elements together leaving them permanently stuck [1]. Release stiction can be alleviated by the use of supercritical drying [1] in which a supercritical fluid is used to dry the parts. Above the critical point there is no vapor liquid transition and surface tension effects due to the liquid are avoided [1]. In-use stiction has been a more difficult problem to overcome.

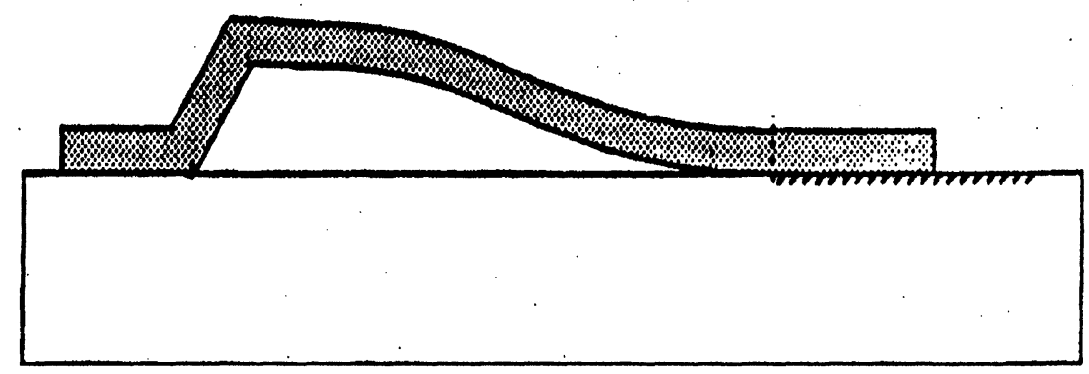

Figure 3. Illustration of Stiction in MEMS Devices [6]. 
The most common techniques to overcome in-use stiction include surface roughening and surface coating [1]. Surface roughening acts to minimize the contact of two surfaces, thus avoiding the surface tension effects. This technique has limited usefulness however, as the roughening treatment usually can only be applied to surfaces that are not shadowed by other elements.

Coating surfaces with materials to lower the surface energy has also been widely examined. The most common technique is to use self-assembled monolayers (SAMs), which are generally silane-coupling agents such as perfluorodecyltrichlorosilane [7]. These agents bind to the silicon surface lowering its surface energy [7]. These treatments are often of limited usefulness as well, as the temperatures of further processing and packaging tend to drive the coupling agent off the wafer.

Factors that have not been thoroughly investigated in their effects on the surface energy of polysilicon include impurity doping. Doping is widely used in the semiconductor industry to alter the electrical properties of polysilicon. Doping silicon with an element with 5 valence electrons, such as phosphorus, will create a free electron, as only 4 of those electrons will participate in the bonding with silicon. The extra electrons provided from the impurity atoms can greatly increase the conductivity of polysilicon. In fact the gate electrode in most MOS circuits is generally fabricated from heavily doped polysilicon as opposed to aluminum [8]. This is due to polysilicon's better compatibility (compared to aluminum) with silicon dioxide, and the ability to withstand higher processing temperatures than aluminum [8]. 
While the effects of impurity doping on the electrical properties of polysilicon are well known, its effects on surface properties are much less documented. Doping of impurities can be accomplished in several ways including coating and diffusion, ion implantation, and in-situ doping during deposition [8]. Each of these methods could potentially have differing effects on the damage done to the surface and the grain structure [8], and thus potentially the surface energy. The size and type ( $\mathrm{n}$ or $\mathrm{p}$ ) of the impurity atom can also have effects on such factors as grain size and film stress [8]. Each of these factors could potentially affect the surface energy of polysilicon and thus stiction between elements fabricated from it.

The emergence of MEMS technology over the last two decades has been a direct result of the utilization of the planar processing technology of the semiconductor industry to make them cost effective. MEMS devices are not only smaller in size than their macro-scale counterparts, which in itself has several technical advantages, but wafer level processing has made them cheaper as well. However, for MEMS devices to become widely commercialized, obstacles such as stiction will need to be resolved. While the effects of polysilicon surface energy on stiction have been investigated to some degree, the effects of doping on the surface energy of polysilicon is an area of research that has yet to be fully studied. This thesis will thus investigate the effects of impurity doping on release stiction of cantilever beams fabricated from polysilicon. 


\section{CHAPTER 2}

\section{LITERATURE REVIEW}

\subsection{Introduction}

The issue of stiction in MEMS devices has undergone substantial research in areas such as surface coatings for reducing surface energy and surface roughening for minimizing surface contact between components. However, both of these techniques have provided only limited usefulness due to a negation of beneficial effects during subsequent processing for coatings and difficulties in front end process integration for surface roughening. While the effects of doping on the electrical properties of polysilicon have been extensively studied, the effects on mechanical and surface properties have received considerably less attention. A literature review of the effects of impurity doping on the material properties of polysilicon has revealed several investigations concerning the effects of doping on surface texture, grain size, surface roughness, and mechanical properties [9-12].

In this review, the effects of impurity doping of polysilicon will be examined in terms of investigations which consider two types of doping effects. Investigations of doping effects on surface properties such as surface texture, roughness, and grain size will be reviewed as each of these considerations may affect the surface energy and thus stiction. The effects of doping on the mechanical properties of polysilicon will also be investigated, as the ability to relate surface energy to stiction will require the fabrication 
of mechanical structures, which would need to be free from excessive stresses for accurate results.

\subsection{Effects of Doping on Surface Properties}

Hedge, Paulson, and Tobin have investigated the effects of phosphorus doping of polysilicon on grain size, surface texture, and surface roughness [9]. In their research, polysilicon films were deposited on thermally oxidized silicon substrates via LPCVD, at two different temperatures. The first group of films was deposited at $625^{\circ} \mathrm{C}$, producing polycrystalline samples of $3500 \AA$ thickness. These films were then subjected to diffusion doping with either $\mathrm{POCl}_{3}$ or $\mathrm{PH}_{3}$ at temperatures of $900^{\circ} \mathrm{C}$ for the $\mathrm{PH}_{3}$ samples and 875,900 , and $950{ }^{\circ} \mathrm{C}$ for the $\mathrm{POCl}_{3}$ samples. The second group of films was deposited at $550{ }^{\circ} \mathrm{C}$ producing an amorphous structure which was in-situ doped using $\mathrm{PH}_{3}$ as the phosphorus source. These films, which were $2800 \AA$ thick, were then annealed at $900^{\circ} \mathrm{C}$ to crystallize the amorphous structure and activate the dopant. All films were etched to remove the thermal oxide which was grown during the doping process.

The films were analyzed in terms of surface texture and surface topography. All samples exhibited (111), (220), and (311) reflections typical of polysilicon, as analyzed by powder diffractometry. Surface topography was analyzed by atomic force microscopy and values for $Z_{r}$, which is the maximum peak to valley distance were reported. Figure 4 illustrates the value of the surface roughness $Z_{r}$ for five of the samples. Samples $A$ and B are the $\mathrm{PH}_{3}$ samples with B having a phosphorus content twice that of A. Samples D 
and $\mathrm{E}$ are the $\mathrm{POCl}_{3}$ samples, annealed at 875 and $900{ }^{\circ} \mathrm{C}$ respectively. Sample $\mathrm{G}$ is the in-situ doped sample with phosphorus content roughly equivalent to $\mathrm{D}$ and $\mathrm{E}$, and twice that of B. In Figure 4 [9], the roughness of the doped films is given with and without the oxide layer. The authors point out that doping increases the surface roughness for all samples, with the $\mathrm{POCl}_{3}$ samples showing the largest effect. The in-situ doped sample has the smoothest surface to begin with and shows little change during subsequent heat treatments.

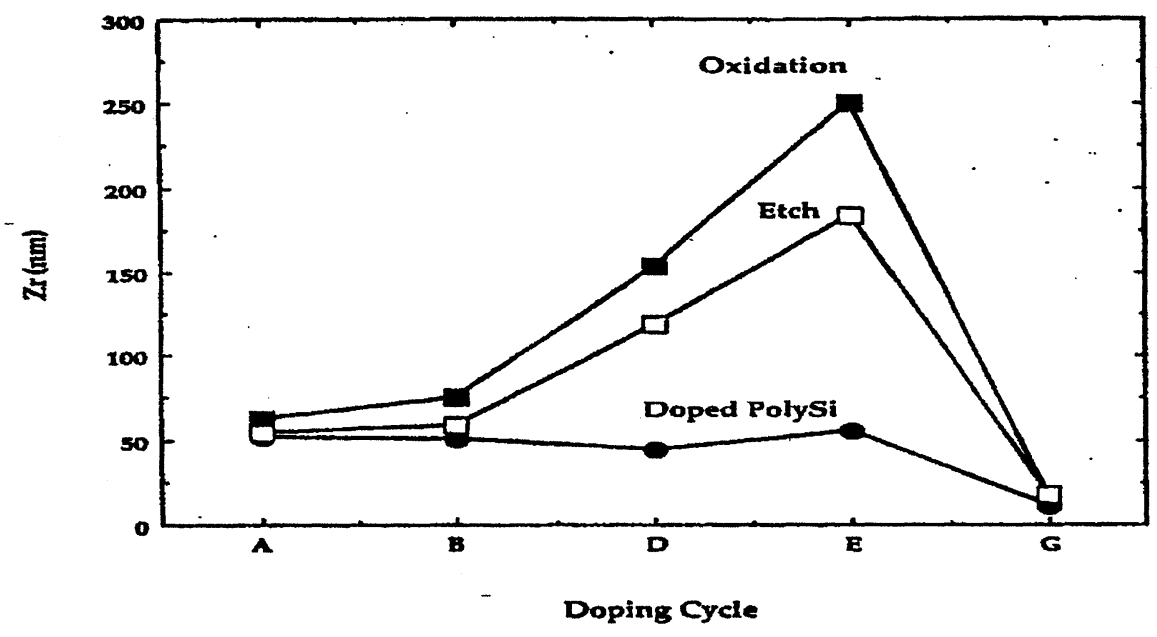

Figure 4. Surface roughness as a function of sample type [9].

In Figure 5 [9], the grain size as determined by AFM is illustrated as a function of sample type. As with the surface roughness, the $\mathrm{POCl}_{3}$ samples show large increases in grain size compared to the others upon subsequent anneal and oxidation. The authors have concluded that the surface roughness and grain size are a function of doping concentration and doping process. The grain size and surface roughness do show a 
strong correlation in that the larger grain sizes produced rougher surfaces. This was attributed to the fact that some grains grew more rapidly at the expense of others for the $\mathrm{POCl}_{3}$ samples. This was attributed to the $\mathrm{Cl}$ in the films, which enhanced grain growth for certain preferred orientations and produced a bi-modal grain distribution in these samples, with the larger grains roughly twice as large as the smaller ones.

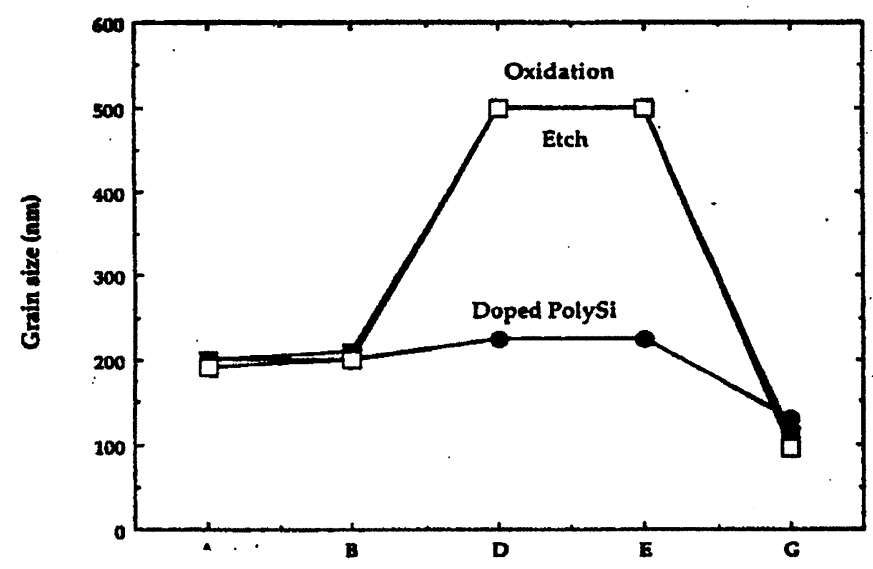

Figure 5: Grain size as a function of sample type [9].

In this study, the grain size and surface roughness do appear to be strongly correlated, however the fact that dopant concentration is the determining factor in this is not at all clear. As can be seen in Figures 4 and 5, sample B has roughly twice the phosphorus concentration as A yet they both have nearly the same roughness and grain size increase. The in-situ sample has an even higher concentration than sample $\mathrm{B}$ yet shows little change. The $\mathrm{POCl}_{3}$ samples do show large changes but this may be due to the $\mathrm{Cl}$ as the authors point out. Also, it is not clear that changes in grain size are due to the dopant or the thermal treatment, as no control sample without doping was subjected to the same thermal treatment. 
Nevertheless, it does appear that the process, considering the combined effects of both dopant and thermal treatment, does affect the surface morphology. These changes in surface morphology most likely would affect the surface energy, which was not measured in this investigation.

The effects of doping on stress and morphology of polysilicon have been investigated by Maier-Schneider et al. [10]. In their study, stress, texture, and grain size were studied as a function of annealing and ion implantation of both boron and phosphorus. Polysilicon films were deposited with LPCVD at $620^{\circ} \mathrm{C}$, with thicknesses ranging from 100 to 800 nanometers and were analyzed with and without doping at various annealing temperatures.

In Figure 6, the authors have plotted the intrinsic stress, as measured by wafer curvature, of $470 \mathrm{~nm}$ thick un-doped poly films as a function of annealing temperature. As is shown in Figure 6, the stress in the as-deposited film is compressive with a value of about $-350 \mathrm{MPa}$. Annealing at progressively higher temperatures decreases this stress to a value close to zero for the $1100{ }^{\circ} \mathrm{C}$ sample. The authors have attributed this stress reduction to elimination of defects, mostly vacancies and dislocations in the as-deposited films, with a corresponding reduction in volume and increase in grain size. 


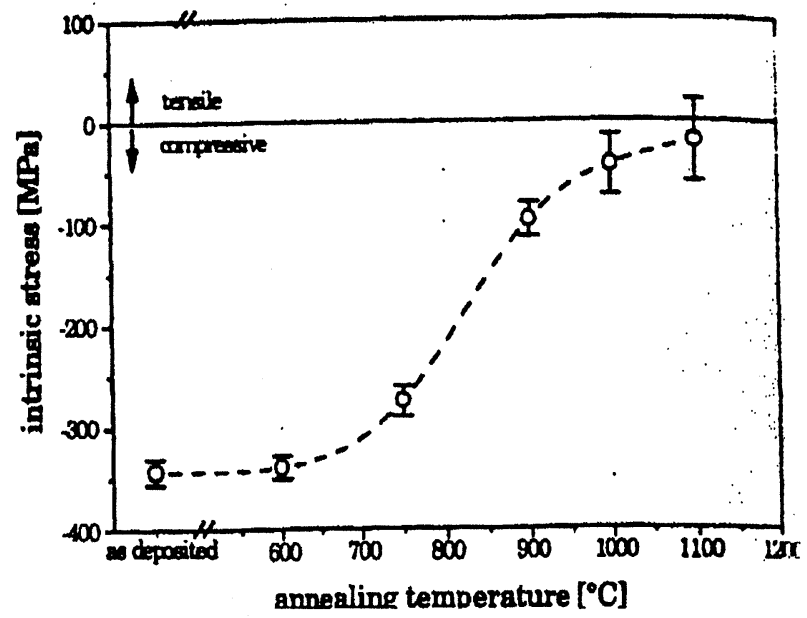

Figure 6. Stress as a function of annealing temperature [10].

The microstructure of the aforementioned films was analyzed with TEM. All films had columnar grain structures with grain sizes of about $55+/-25 \mathrm{~nm}$ for films annealed below $1000{ }^{\circ} \mathrm{C}$ and a grain size of $116+/-56 \mathrm{~nm}$ for the film annealed at 1100 . ${ }^{\circ} \mathrm{C}$. The films annealed below $1000{ }^{\circ} \mathrm{C}$ showed no change in the predominant $(110)$ texture. The $1100{ }^{\circ} \mathrm{C}$ sample, which did show a doubling in the mean grain size, did show a small change in the texture distribution. This type of behavior, as seen in the study by Hedge [9], leads to a larger distribution in grains sizes, as seen in this study. The study by Hedge [9] also indicates that this increase in grain size and size distribution leads to a rougher surface as preferentially oriented grains grow at the expense of others.

Films were also analyzed as a function of doping with boron and phosphorus. Films were doped with either boron or phosphorus by ion implantation, with doses ranging from $10^{11}$ to $10^{16} \mathrm{~cm}^{-1}$. Residual stress for both types of films as a function of implant dose and thermal treatment are illustrated in Figures 7 and 8 [10]. As can be seen 
in Figure 7, doping has virtually no effect on stress for films implanted with boron with the exception of the highest implant dose sample, in which a significant increase in the compressive stress is observed. For the phosphorus doped sample, Figure 8, a slight decrease in the compressive stress is seen for the first 4 samples with an increase in the compressive stress for the last sample. The authors have explained this behavior in that two mechanisms are involved in altering the stress. The first mechanism is damage to the crystal structure by the high energy ions during the implantation process, which would tend to decrease the compressive stress in the sample due to breaking of bonds, which would relieve lattice strains. For the relatively small and light boron ions, little damage to the crystal structure is expected and no decrease in stress would be expected due to this mechanism as shown in Figure 7. The larger and heavier phosphorus ions are capable however of producing more damage to the lattice, which is manifested as a gradual decrease in the compressive stress for the first four samples as illustrated in Figure 8. 


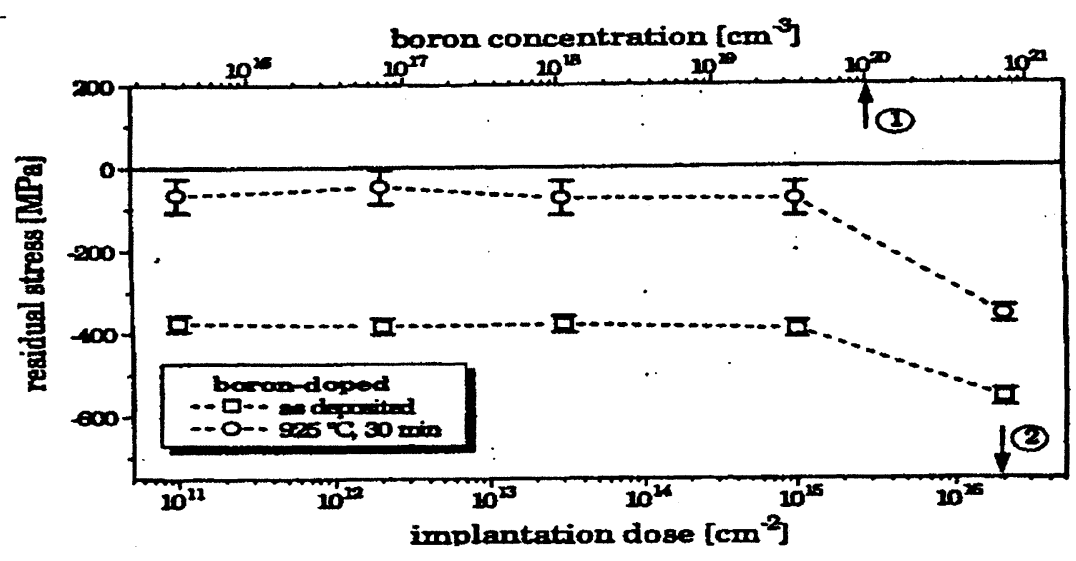

Figure 7. Stress as a function of implant dose and annealing for boron [10].

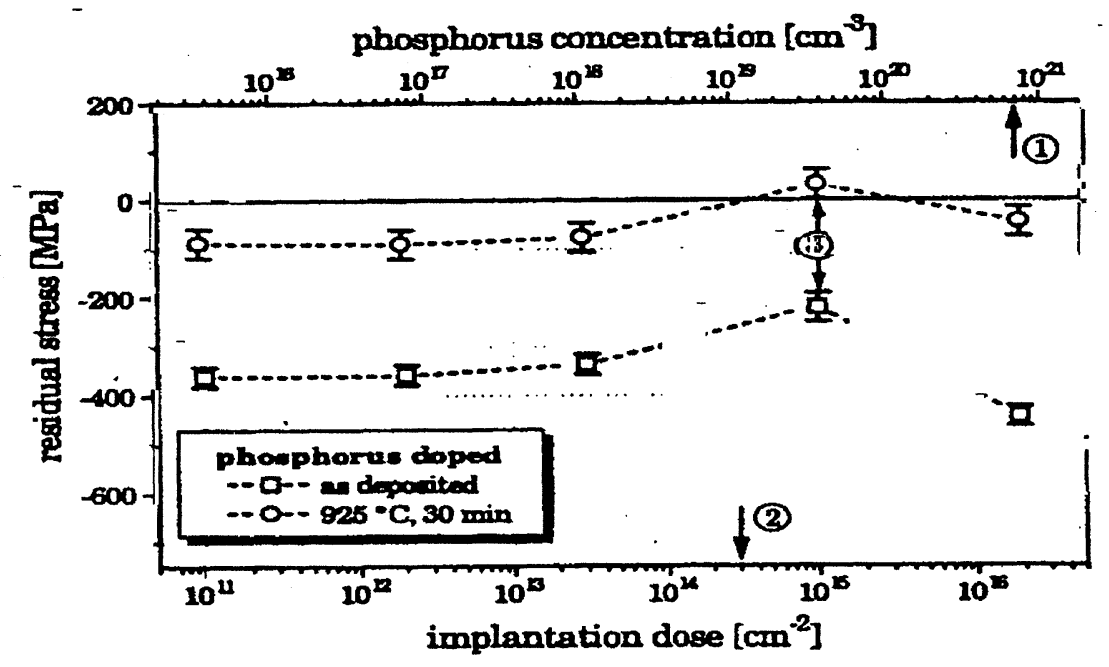

Figure 8. Stress as a function of implant dose and annealing for phosphorus (10).

The second mechanism involves strains caused by the impurity ions. In both Figures 7 and 8, the last sample shows a significant increase in the compressive stress. Both of these samples had implant doses which resulted in the sample being doped above the saturation level. This high level of doping, the authors concluded, led to increased 
compressive stress due to lattice distortions caused by ions incorporated into the silicon lattice and those segregated at grain boundaries.

As can be seen in both figures, annealing of both types of doped samples reduced the compressive stress. For the boron doped samples, the compressive stress was reduced to values similar to that of the un-doped samples. The phosphorus doped samples exhibited a decrease in compressive stress as well, although to a lesser extent, illustrating the importance of the impurity atom size in the stress.

This study is significant in that it examines the contributions of doping to morphology in terms of implanting and annealing. In the study by Hedge [9] the relative effects of the thermal treatment and doping could not be separately determined. In the study by Maier-Schneider et al. [10], the relative contributions of annealing and doping have been separated. This study, along with the previous, also gives insight into the differences between diffusion doping and ion implantation, as well as the influence of ion size. Ion implantation clearly causes more surface damage, depending on the ion, which has effects on residual stress. However, along with the previous study, the effects of the differing process parameters on surface energy were not established.

To relate surface effects to stiction, the fabrication of test beams is usually required. These usually consist of cantilever beams of varying lengths, which are electrically actuated such that they are electrostactically attracted to the polysilicon surface. The length at which a certain percentage become stuck to the polysilicon surface represents the point at which surface effects become significant leading to stiction. In 
order to obtain accurate results, beams fabricated from polysilicon must be relatively free from excessive stresses. Several studies have examined stress in doped polysilicon .

Elbrecht, et al. [11] have investigated the stress in highly phosphorus doped polysilicon deposited by LPCVD. Films of $500 \mathrm{~nm}$ thickness were first deposited at temperatures between 560 and $630{ }^{\circ} \mathrm{C}$ and the stress was determined by measuring wafer curvature. Below temperatures of $600^{\circ} \mathrm{C}$, films which were initially completely amorphous displayed a relatively constant tensile stress of about $250 \mathrm{MPa}$ after a recrystallization treatment at $650{ }^{\circ} \mathrm{C}$. In samples deposited above $600{ }^{\circ} \mathrm{C}$ (which were crystalline) the tensile stress steadily decreased to a value of $-400 \mathrm{MPa}$ compressive, which corresponds well to the values of Maier-Schneider et al. [10] for the same processing temperature. Following the $650^{\circ} \mathrm{C}$ re-crystallization anneal, the films deposited at $585^{\circ} \mathrm{C}$ were then subjected to diffusion doping at $850{ }^{\circ} \mathrm{C}$ for various times. Results are illustrated in Figure 9. As can be seen in Figure 9, the tensile stress decreases and eventually turns compressive as the phosphorus concentration increases. Annealing treatments at temperatures above $1000{ }^{\circ} \mathrm{C}$ reduce the compressive stress to values close to zero. This annealing behavior was also observed by Maier-Schneider et al. [10]. These results indicate that the relatively large phosphorus atoms increasingly add compressive stress to the silicon matrix, as would be expected. 


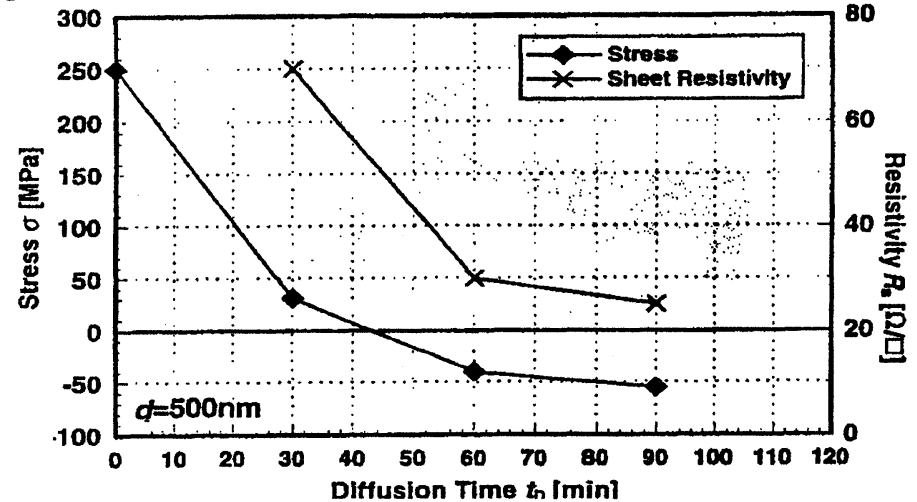

Figure 9. Stress as a function diffusion time for phosphorus [11].

The study by Elbrecht, et al. [11] has also examined stress gradients in the doped films. Stress gradients could lead to bending moments in free standing structures such as cantilever test beams. Stress profiles were determined by continually etching away the top surface of the films and measuring the resultant stress. Results for stress gradients in the films are illustrated in Figure 10. As can be seen in Figure 10, the stress is compressive near the surface of the sample, eventually turning tensile (the samples original stress state) progressively further below the surface. The concentration profile of the phosphorus thus contributes to the compressive stress through the sample. 


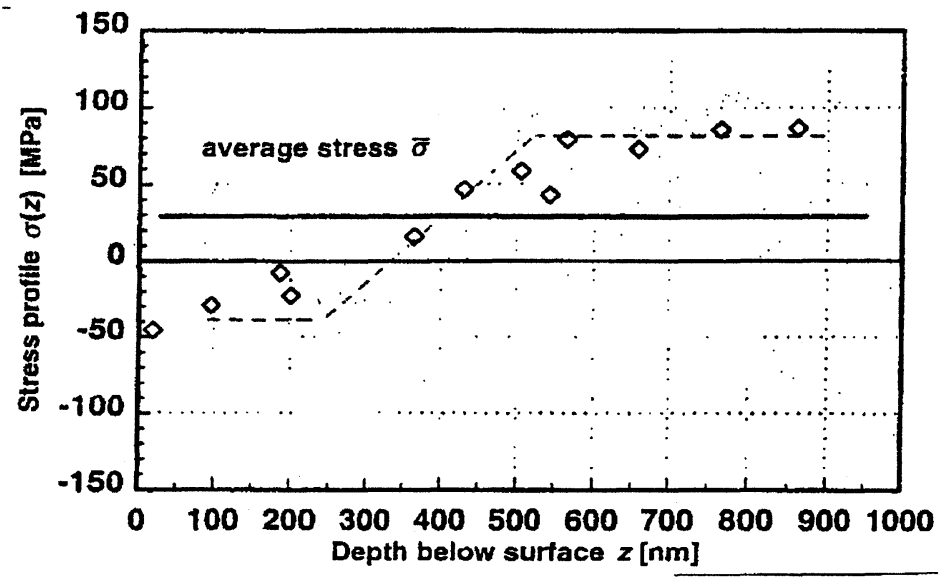

Figure 10. Stress gradient for phosphorus doped samples [11].

This study shows the effects of phosphorus doping in terms of the magnitude of the stress it can generate. The previous study by Maier-Schneider et al. [10] examined stress as a function of doping from samples which were initially compressive. Those samples did not show further increases in compressive stress except at very large doping levels in which the maximum solubility was exceeded. The study by Elbrecht et al. [11] showed significantly increasing levels of compressive stress at lower doping levels, as the films were initially tensile. This study also gives significant information on stress gradients in polysilicon due to doping. Non-uniform dopant concentrations through the thickness of the film can lead to stress gradients which can lead to bending moments in free standing structures such as cantilever beams. This would need to be taken into consideration during the fabrication of cantilever test samples.

Furtsch et al. [12] have also studied the effects of stress in phosphorus doped films. LPCVD poly films were diffusion doped with phosphorus from $\mathrm{POCl}_{3}$ and 
subjected to different annealing treatments. Three samples were annealed according to Table 1 and the resulting stress gradient was measured.

As can be seen in Table 1, the stress gradients become increasingly compressive as the oxygen treatment increases. The authors have concluded that the ambient of the annealing furnace has a strong effect on the stress state of the grains near the surface of the sample, with an oxygen ambient leading to compressive stress and a subsequent downward bending of fabricated structures.

Table 1: Annealing Process and Stress Gradients [12].

\begin{tabular}{|c|l|c|}
\hline $\begin{array}{l}\text { Sample } \\
\#\end{array}$ & Annealing Procedure & $\begin{array}{l}\text { Stress Gradient } \\
(\mathrm{MPa} / \text { micron})\end{array}$ \\
\hline 1 & $\mathrm{~N}_{2}, 1100^{\circ} \mathrm{C}, 7 \mathrm{~h}:+\mathrm{N}_{2} 1000^{\circ} \mathrm{C}$ & $+1.62+/-0.11$ \\
& $0.5 \mathrm{~h}$ & \\
\hline 2 & $\mathrm{~N}_{2}, 1100^{\circ} \mathrm{C}, 7 \mathrm{~h}:+\mathrm{O}_{2} 100{ }^{\circ} \mathrm{C}$ & $-0.11+/-0.14$ \\
& $0.5 \mathrm{~h}$ & $-6.23+/-0.26$ \\
\hline 3 & $\mathrm{O}_{2} 120{ }^{\circ} \mathrm{C} 2 \mathrm{~h}$ & \\
\hline
\end{tabular}

The study of Furtsch et al. [12] has indicated the importance of the furnace ambient during annealing and/or diffusion doping, however it does not include any data on the mechanism causing such a behavior. It also lacks data on the relative contributions of phosphorus, compared to oxygen or nitrogen, to the stress gradient as no 
non-doped control sample was included. It does possibly indicate that nitrogen atmospheres are beneficial as the sample which was treated twice in nitrogen (sample 1) showed no change on further treatments.

\subsection{Stiction Effects for Cantilever Beams}

Tas et al. [13] have investigated the causes of both release and in-use stiction and methods for reducing these effects. Forces that contribute to stiction according to the authors include capillary forces, electrostatic forces, hydrogen bridging, and Van der Waals forces. The authors also present an equation for calculating the critical length of beam which is likely to stick if brought into contact with the wafer surface, with the critical length being a function of the surface energy, the modulus of the material in question, and beam dimensions.

Also presented are methods for reducing in-use stiction, which include physically altering the surface to reduce contact area as well as chemically altering the surface to make it hydrophobic. This type of modification they suggest has the effect of reducing the amount of water on the wafer, reducing capillary forces which may pull beams into contact with the substrate.

De Boer and Michalske [14] have investigated the adhesion of cantilever beams on wafers treated to give hydrophobic or hydrophilic surfaces. For hydrophilic beams, the shortest beams to stick were 58 microns compared to a value of 120 microns for the hydrophobic beams, showing the effects of surface energy on adhesion. The authors have also concluded that surface adhesion values are best measured with beams attached 
to the substrate in the "S" shape as opposed to the "arc" shape due to various factors including surface roughness.

Legtenberg et al. [15] have investigated the effects of hydrophobic and hydrophilic surfaces on release stiction for doubly attached beams, ranging in size from 10 to 200 microns in length and 20 to 50 microns in width. Hydrophobic surfaces were obtained by etching the sacrificial oxide layer in $\mathrm{HF}$ and then rinsing in DI water, leaving the bottom silicon surface extremely hydrophobic. Hydrophilic wafers were prepared by immersing the released wafers into a nitric acid solution after rinsing, creating a thin $\mathrm{SiO}_{2}$ layer, rendering the surface hydrophilic.

The authors measured the detachment length (the shortest length beams which ceased to stick) for the two different surfaces, and the hydrophobic wafers had larger detachment length than the hydrophilic wafers. They also reported a larger amount of scatter in the data for the hydrophobic wafers, with many long beams not sticking and shorter ones remaining stuck. For the hydrophilic beams, there was less scatter and a better defined detachment length. The authors observed that all beams greater than the critical pull-down length were pulled down during release for both cases, however many deflected off the surface after complete drying.

The authors also surmised that surface roughness effects could explain some of the differences in the amounts of stiction for both groups, as wafers with rougher surfaces would be expected to have less surface contact area, and thus less chance of a beam sticking to the surface when it was pulled down during drying. 
This study presents a substantial amount of data on the effects of different surfaces on release stiction, however it does not give any data on the numbers of beams analyzed or if the same trends were observed for replicate groups. A better discussion of the sample size and whether there was a clear demarcation between beams that stuck and those that did not stick would have been more helpful.

The effects of doping on selected morphological and mechanical properties of LPCVD polysilicon have been examined through a search of previous work in this field. The effects of different doping techniques, including diffusion and ion implantation, as well as dopant type and size, boron versus phosphorus, have been examined in terms of surface roughness, grain structure, and film stress. The importance of stress gradients for cantilever structures as well as furnace ambient, which can contribute to stress gradients, have also been examined. The effects of surfaces on release stiction, both in terms of surface energies (hydrophobic and hydrophilic) and surface roughness effects have been studied to some extent, although most are lacking in statistical analysis. The effects of these types of doping processes on the surface energy and release stiction were examined in this thesis. 


\section{CHAPTER 3}

\section{EXPERIMENTAL}

\subsection{Research Objective}

This thesis investigated the effects of impurity doping on release stiction of cantilever beams fabricated from polysilicon films. Several different aspects were investigated, including dopant type, dopant level, as well as the effects of doping only one or both of the polysilicon surfaces which come into contact during fabrication or use.

The effect of dopant type was investigated by doping with boron and phosphorus. These two impurity types provided information on the effects of atom size, with phosphorus being more than three times as heavy as boron ( $31 \mathrm{vs} .10 .8 \mathrm{~g} / \mathrm{mol}$ ). This effect may be most significant during ion implantation, with the heavier phosphorus atom likely to cause more lattice damage. It also illustrated possible differences due to the electrical characteristics of each ( $n$ versus $p$ type) dopant.

The effects of dopant level were investigated by doping at two extreme implantation doses for both boron and phosphorus. A low dose of approximately $10^{11}$ ions $/ \mathrm{cm}^{2}$ was used as the low extreme and a dose of approximately $10^{16}$ ions $/ \mathrm{cm}^{2}$ for the high limit.

Beams were fabricated from wafers consisting of a structural polysilicon layer with a sacrificial LTO layer beneath this polysilicon layer, and a surface polysilicon layer beneath the LTO layer which the beams could potentially come into contact with (see Figure 12). The effect of doping only the surface polysilicon layer versus both the 
surface polysilicon layer and the structural polysilicon layer was also investigated. The surface polysilicon layer (the surface the cantilever beam could come in contact with and potentially stick to) was subjected to ion implantation of either boron or phosphorus at two extreme doses. A second sub-group of these wafers was also subjected to doping of the structural polysilicon layer (the layer which beams were fabricated from) by a drive in diffusion from a spin-on-glass and thermal anneal. These experiments provided insight into the effects on stiction of impurity doping on both the surface the beam comes in contact with, as well as the effects of doping the structural layer (from which the beam is fabricated).

\subsection{Research Approach: Wafer Processing}

The overall approach for fabricating wafers consisted of several deposition and etching steps. Polysilicon layers were deposited for the bottom surface layer and the top structural layer, with a sacrificial oxide layer deposited in between these layers. The bottom polysilicon layer was subjected to ion implantation of either phosphorus or boron for all wafers, with the exception of the control wafers which had no doping. A subset of the ion-implanted wafers was also subjected to a diffusion doping of the top structural layer with phosphorus. Beam structures were defined by photolithography, reactive ion etching, and wet etching. The released structures were then analyzed for stiction effects via optical interferometry. A flow diagram is illustrated in Figure 11.

As can be seen in Figure 11, the first step in the fabrication was a thermal oxidation of the starting wafers. All wafers were subjected to a RCA clean, and then 
subjected to a wet oxidation at $1100{ }^{\circ} \mathrm{C}$. A polysilicon film of $7000 \AA$ (surface poly layer) was then deposited on the oxidized surface in a horizontal tube furnace operated at $620{ }^{\circ} \mathrm{C}$ (all flow rates and operating pressures are tabulated in Appendix A). This polysilicon surface served as the bottom surface of the test structure, and thus was the surface to be subjected to ion implantation. Boron and phosphorus at two doses $\left(10 \times 10^{11}\right.$ and $10 \times 10^{16} \mathrm{ions} / \mathrm{cm}^{2}$ ) were implanted into this surface at an energy of $100 \mathrm{keV}$. Control wafers had no implantation of this layer. The matrix of wafers, along with their doping conditions, is summarized in Table 2.

A film of low temperature oxide (LTO) was next deposited onto the wafers at a thickness of approximately $20,000 \AA$. This was also accomplished in a horizontal tube furnace operated at $400{ }^{\circ} \mathrm{C}$ (all operating conditions are tabulated in Appendix A). This oxide layer served as the sacrificial layer between the bottom polysilicon layer and the top structural polysilicon layer, and when later etched away, would release the beams into free standing structures. 


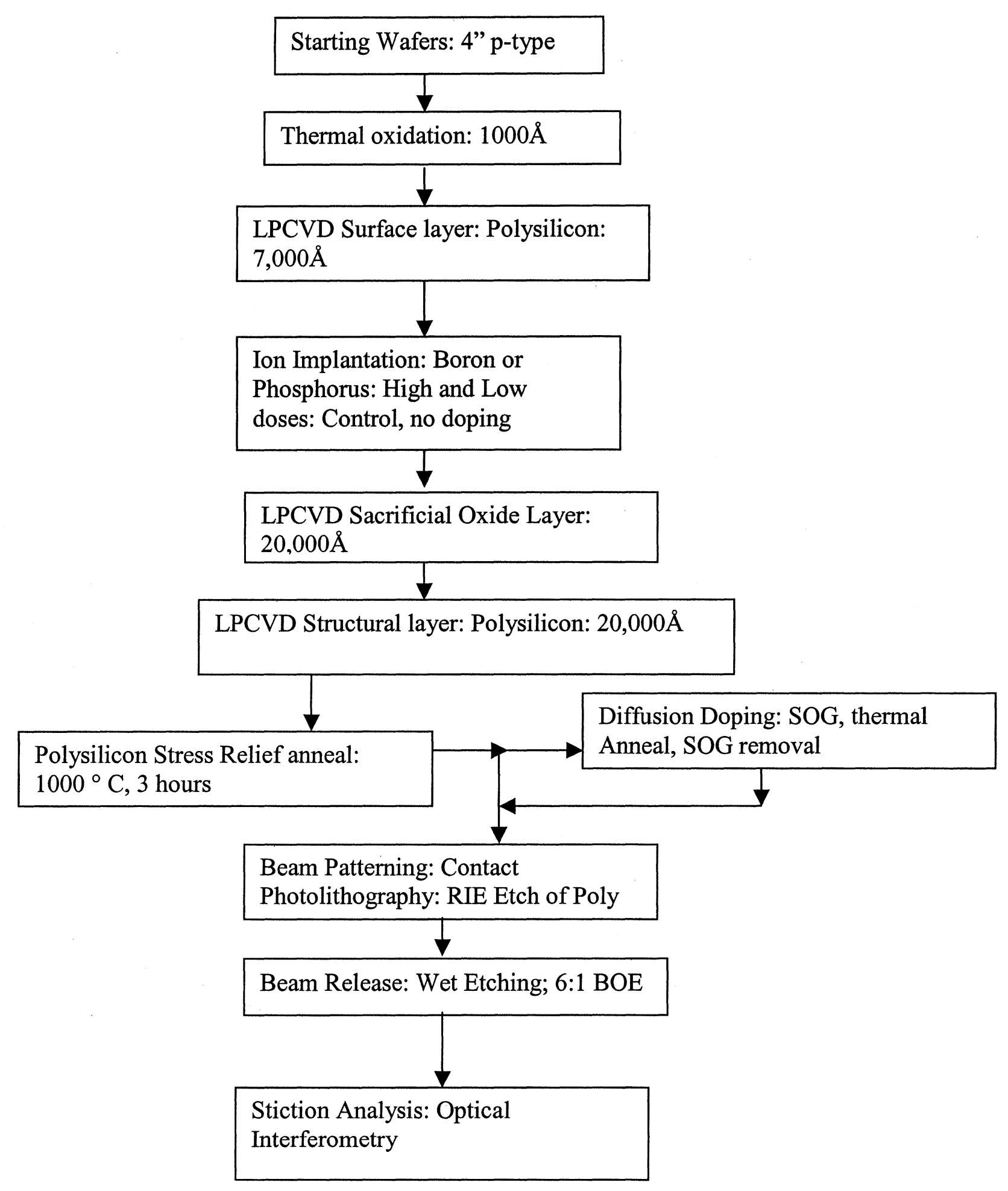

Figure 11. Flow Diagram for Beam Fabrication Process. 
Table 2. Wafer Doping Matrix.

\begin{tabular}{|c|c|c|}
\hline Group/Wafer & $\begin{array}{c}\text { Surface Layer Dose: } \\
\text { Ions } / \mathrm{cm}^{2}\end{array}$ & $\begin{array}{c}\text { Structural Layer Dose } \\
\text { Ions } / \mathrm{cm}^{2}\end{array}$ \\
\hline \multicolumn{3}{|l|}{ Group 1} \\
\hline Wafer PH4 & Phosphorus: $10^{16}$ & None \\
\hline Wafer PL1 & Phosphorus: $10^{11}$ & None \\
\hline Wafer BH3 & Boron: $10^{16}$ & None \\
\hline Wafer BL4 & Boron: $10^{11}$ & None \\
\hline Wafer C8 & None & None \\
\hline \multicolumn{3}{|c|}{$\begin{array}{c}\text { Group } 2 \text { (Group } 1 \\
\text { Replicate) }\end{array}$} \\
\hline Wafer PH2 & Phosphorus: $10^{16}$ & None \\
\hline Wafer PL2 & Phosphorus: $10^{11}$ & None \\
\hline Wafer BH1 & Boron: $10^{16}$ & None \\
\hline Wafer BL2 & Boron: $10^{11}$ & None \\
\hline Wafer C7 & None & None \\
\hline \multicolumn{3}{|c|}{ Group 3( Structural } \\
\hline Wafer PL2 & Phosphorus: $10^{11}$ & $\begin{array}{c}\text { Phosphorus: Saturation } \\
\text { Condition }\end{array}$ \\
\hline Wafer BL1 & Boron: $10^{11}$ & $\begin{array}{c}\text { Phosphorus: Saturation } \\
\text { Condition }\end{array}$ \\
\hline Wafer C10 & None & $\begin{array}{c}\text { Phosphorus: Saturation } \\
\text { Condition }\end{array}$ \\
\hline
\end{tabular}


The structural polysilicon layer was next deposited in the tube furnace at the same conditions as the surface polysilicon layer. This layer however, was grown to a thickness of $20,000 \AA$. The actual beam structures were patterned from this layer. After this deposition, all wafers were subjected to a stress relief anneal, which consisted of 3 hours at $1000{ }^{\circ} \mathrm{C}$ in a nitrogen ambient. This anneal process was determined by measuring the wafer curvature (and thus the film stress) of test wafers before and after anneals of varying times.

Wafers were next divided into three groups, two of which were subjected to beam patterning, and the other to diffusion doping of the top structural poly layer before beam patterning. Diffusion doping (of phosphorus) was accomplished by depositing a $3000 \AA$ layer of phosphosilicate glass on wafers by spin coating and then annealing in a tube furnace at $1000{ }^{\circ} \mathrm{C}$ in a nitrogen ambient for 45 minutes. After the anneal, the glass layer was removed by wet etching in 6:1 buffered oxide etch (BOE). These wafers, along with the two wafer groups which were not doped with the phosphosilicate glass, were then patterned into the beam test structures. This was accomplished by spin coating a 1.6 micron layer of positive photoresist onto the wafers and exposing them on a contact aligner using a clear field mask to pattern the beam structures. Exposed wafers were then developed and hardbaked, completing the transfer of the mask pattern into the photoresist. This photoresist pattern would then serve as the etch mask for the patterning of the polysilicon structural layer.

The transfer of the photoresist pattern into the polysilicon structural layer 
was accomplished by reactive ion etching. A Freon and $\mathrm{SF}_{6}$ mixture was used to etch the polysilicon layer down to the oxide layer with minimal undercut of the photoresist etch mask. Once the polysilicon was etched, the photoresist was stripped in heated sulfuric acid and hydrogen peroxide (piranha) bath. All operating conditions for the etch reactor are tabulated in Appendix A.

The final step in device fabrication was the release of the beam structures. This was accomplished by wet etching the sacrificial oxide layer, both in the field and under the beams, by immersion in 6:1 $\mathrm{BOE}$. Etch indicators in the form of squares ranging from 10 to 30 microns on edge were monitored to determine the amount of undercut during the etch. The etch was terminated once the 20 micron etch indicator was etched clean of the wafer. This would indicate that the beams, which were 20 microns wide, were completely undercut (all the oxide removed under the beam). Once the etch was finished, the wafers were allowed to air dry for 48 hours prior to the first examination and then allowed to dry for an additional seven days prior to a second examination. Illustrations of the final released beam structures are shown in Figures 12 and 13. 


\section{Final Structure: Side View}

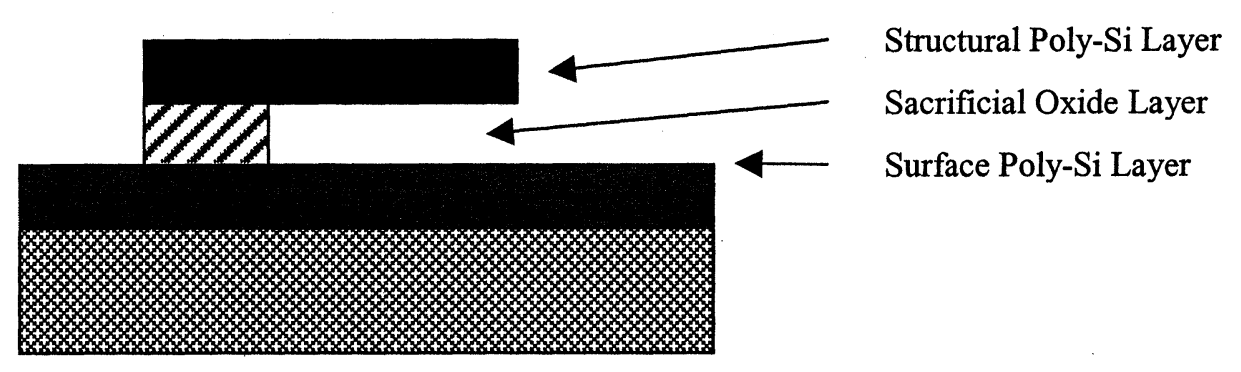

Figure 12. Side view of released beam structure.

\section{Top View}

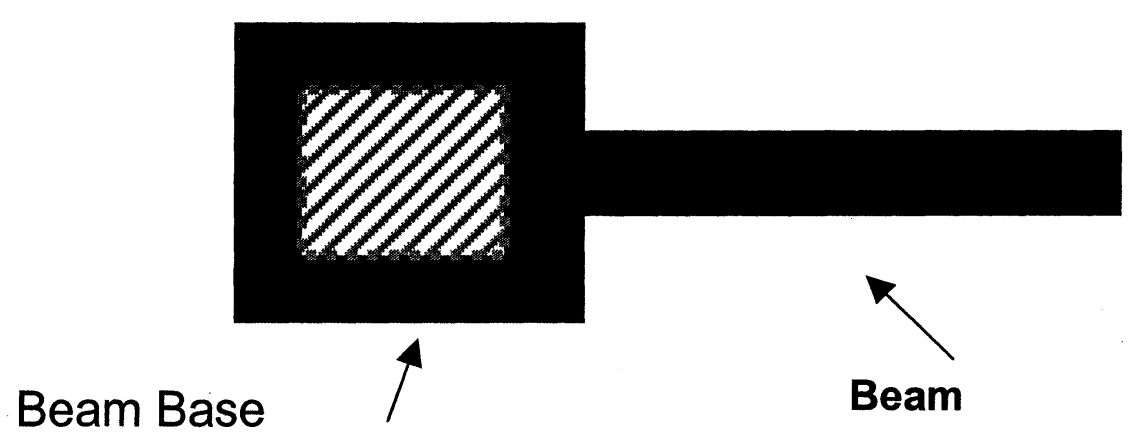

Figure13. Top view of released beam structure

\subsection{Stiction Analysis}

Examination of the beam structures was accomplished by optical interferometry.

A Zygo white light interferometer with a 20X objective was used for determining whether beams were stuck to the surface of not. Changes in the fringe pattern (both fringe width and spacing) were used to make a qualitative determination of beam 
deflection. Analysis by the Zygo software program was used to determine quantitative measurements of beam heights and deflections. Data collected from this analysis included height of beam structure at the base and the tip, number and size of beams stuck to wafer, and the type of stiction involved ( "s" or "arc" shaped stiction). For each wafer, 7 individual beam groups, each consisting of three rows of 17 beams, were examined for a total of 357 beams analyzed for each doping condition. Beams ranged in size from 60 to 400 microns in length in 20 micron increments, and had a width of 20 microns. The same groups were analyzed for each wafer, with the exception of groups in which the etch undercut indicators did not indicate full release, in which case the neighboring beam group was analyzed. Locations of the beam groups which were analyzed are illustrated in Figure 14, which gives the layout of the beam mask design, with the beam groups outlined in black analyzed for stiction.

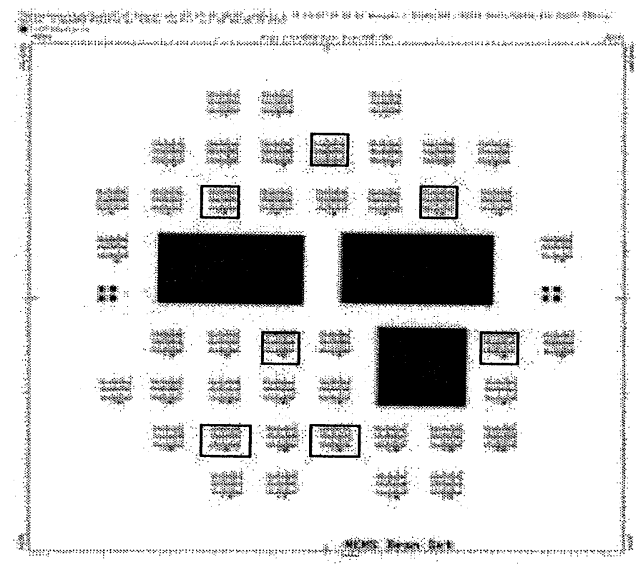

Figure 14. Beam layout for stiction analysis: 42 die per wafer. 
The layout of each individual die is illustrated in Figure 15, which shows the features of each die. These features include three identical rows of beams ranging from 60 to 400 microns in length in 20 micron increments, as well as etch undercut indicators, which allowed for determining when a beam was fully released.

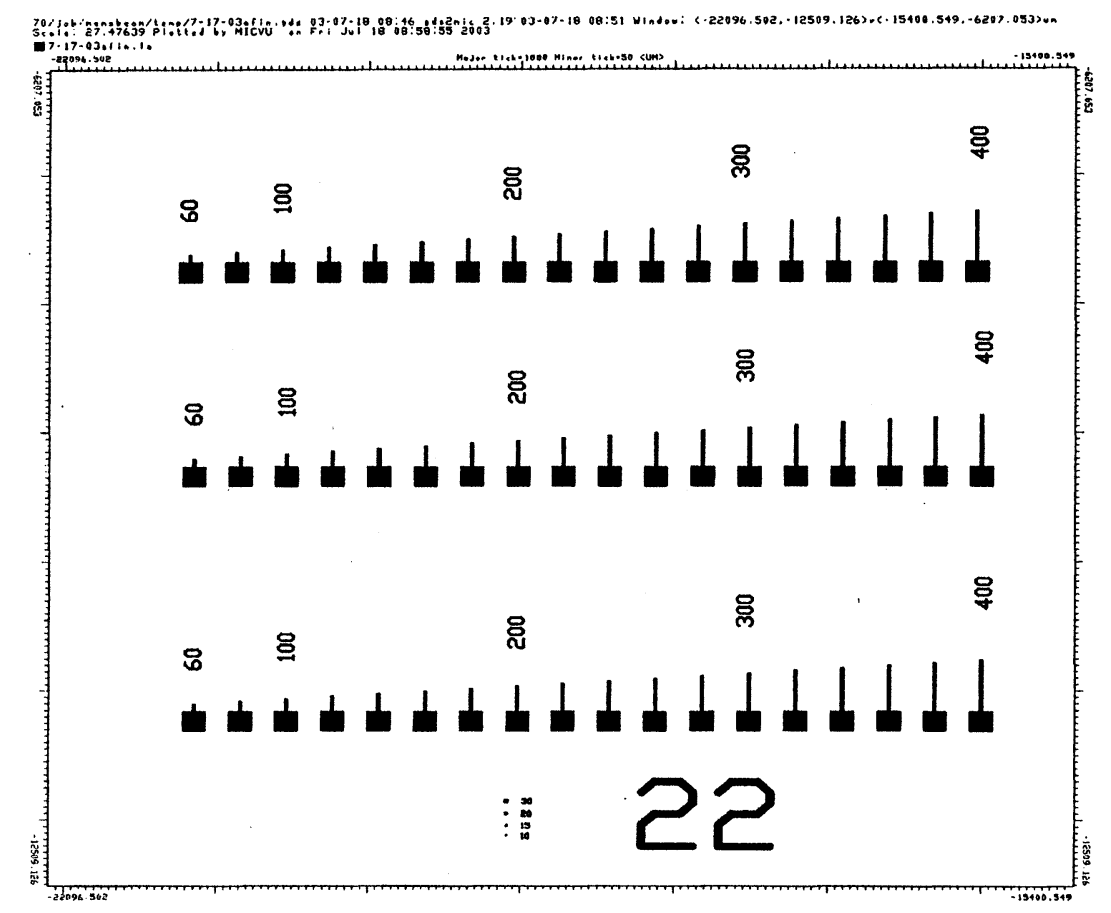

Figure 15. Individual beam group (die) for stiction analysis. 


\section{CHAPTER 4}

\section{RESULTS}

\subsection{Results: Device Fabrication}

\subsubsection{Polysilicon Film Stress Relief}

Quantitative stress measurements of polysilicon thin films for the beam structural layer were employed to determine the appropriate anneal time for stress reduction. To insure beams with minimal curvature when the structural poly-Si layer was patterned and released, it was necessary to reduce the film stress in the structural layer to close to zero. For the polysilicon structural layer film, the intrinsic film stress was measured on a test wafer as a function of anneal time at $1000{ }^{\circ} \mathrm{C}$ in a nitrogen environment. Results for the anneal are illustrated in Figure 16.

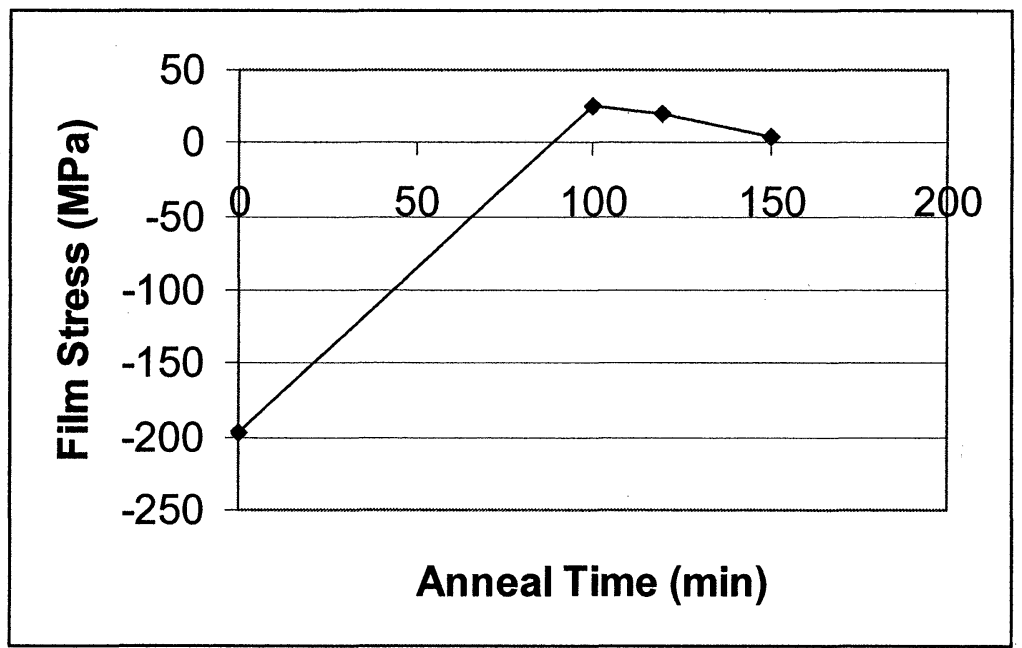

Figure 16. Structural layer polysilicon film stress as a function of anneal. 
As can be seen in Figure 16, the film stress for the as-deposited un-doped film was $-197 \mathrm{MPa}$, with the negative value indicating a compressive film stress. At about 90 minutes, the stress crosses over from tensile to compressive and converges to zero with increasing anneal time. At 150 minutes anneal time, the value of the film stress is reduced to $4 \mathrm{MPa}$ compressive, which would translate into beams with very minimal curvature when released. A test wafer with a 150 minute anneal was patterned and released and SEM results are illustrated in Figure 17, which indicates no significant curvature of the annealed beam. All sample wafers were given a 180 minute, $1000{ }^{\circ} \mathrm{C}$ anneal for structural layer film stress reduction.

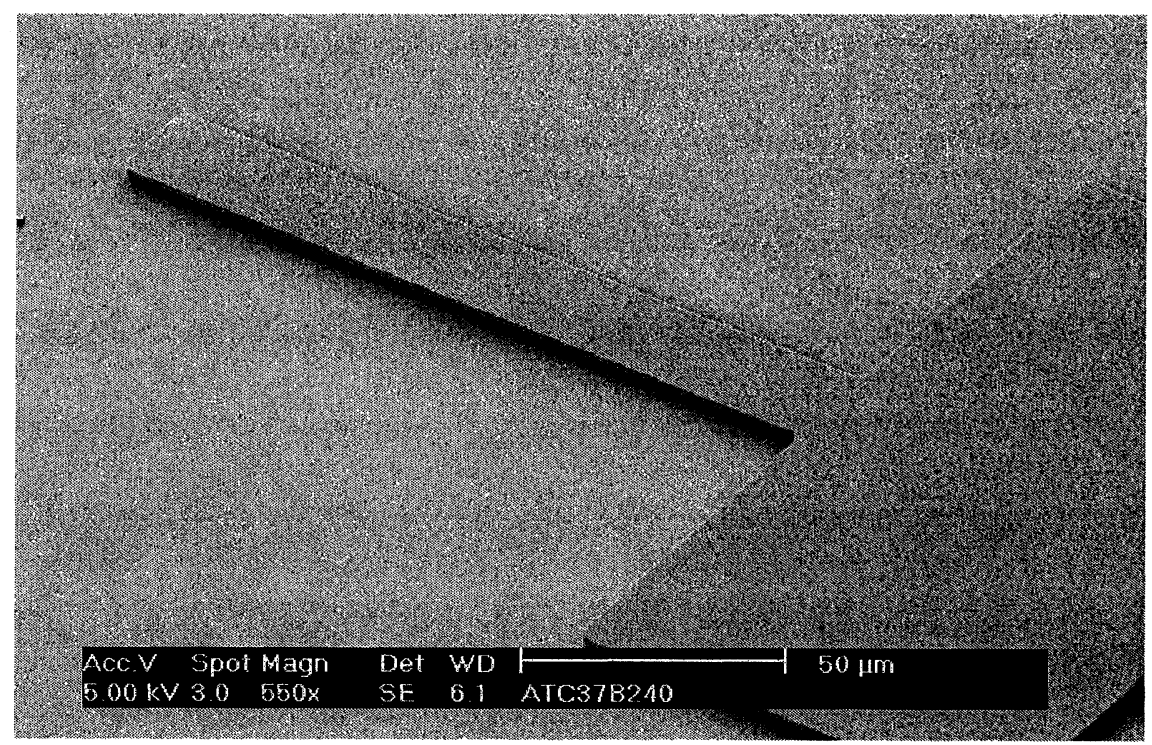

Figure 17. SEM of low stress beams: 180 minute $1000^{\circ} \mathrm{C}$ anneal.

Beam curvature was measured for all samples via optical interferometry, by measuring the height of the base and the height of the end of one 400 micron beam from 
beam group 7 after etch release. Results are illustrated in Figure 18, which shows that most beams had very little difference in height between the base and end, indicating little or no curvature. Several of the beams however, show up to a 0.9 differential in height between the base and end, indicating small beam stresses. As all wafers were annealed in the same anneal run, there was obviously a difference in either the initial film stress (from the poly deposition) or a difference in annealing behavior in the anneal furnace. The wafer ID's "PH" and "BH" refer to phosphorus high and boron high doping conditions respectively. The ID's "PL" and "BL" refer to phosphorus low and boron low doping conditions. The ID "C" refers to the control condition, in which the bottom poly layer was not subjected to ion implantation (see Table 2).

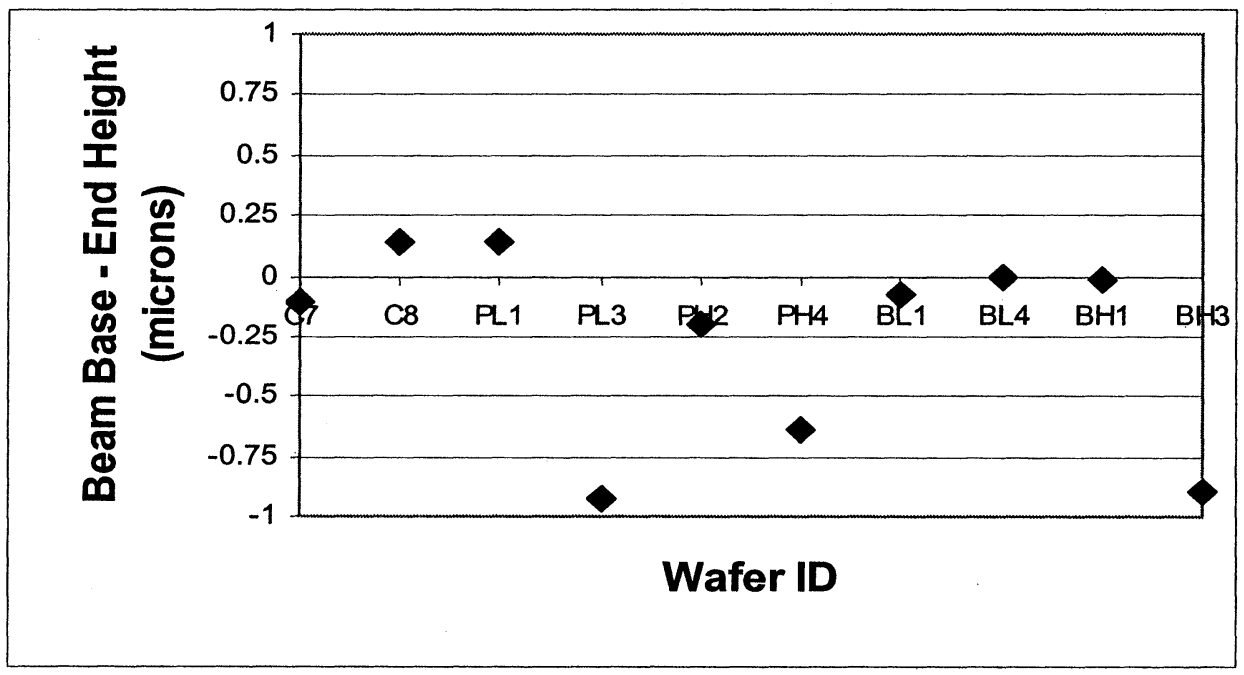

Figure 18. Difference between beam base and end height.

\subsubsection{Film Thickness Effects}

To examine any possible effects of differences in spacing between the beam structural layer (the bottom of the beam) and the surface (doped) poly layer (see Figure 
12), an examination of the sacrificial oxide layer thickness was performed. The thickness of the sacrificial oxide layer determined the spacing of the beam/substrate gap, and possible large variations in this thickness may influence degrees of stiction. Larger gap spacings would require a larger force to pull the beam to the substrate and make it stick. The average values of the oxide thickness are shown in Figure 19. To determine if there was any statistical difference in the values for the mean oxide thickness displayed in Figure 19, an analysis of variance (ANOVA) was performed on the oxide thickness data, with the different measurements for each condition being used as replicate groups. Results for this calculation are tabulated in Table 3.

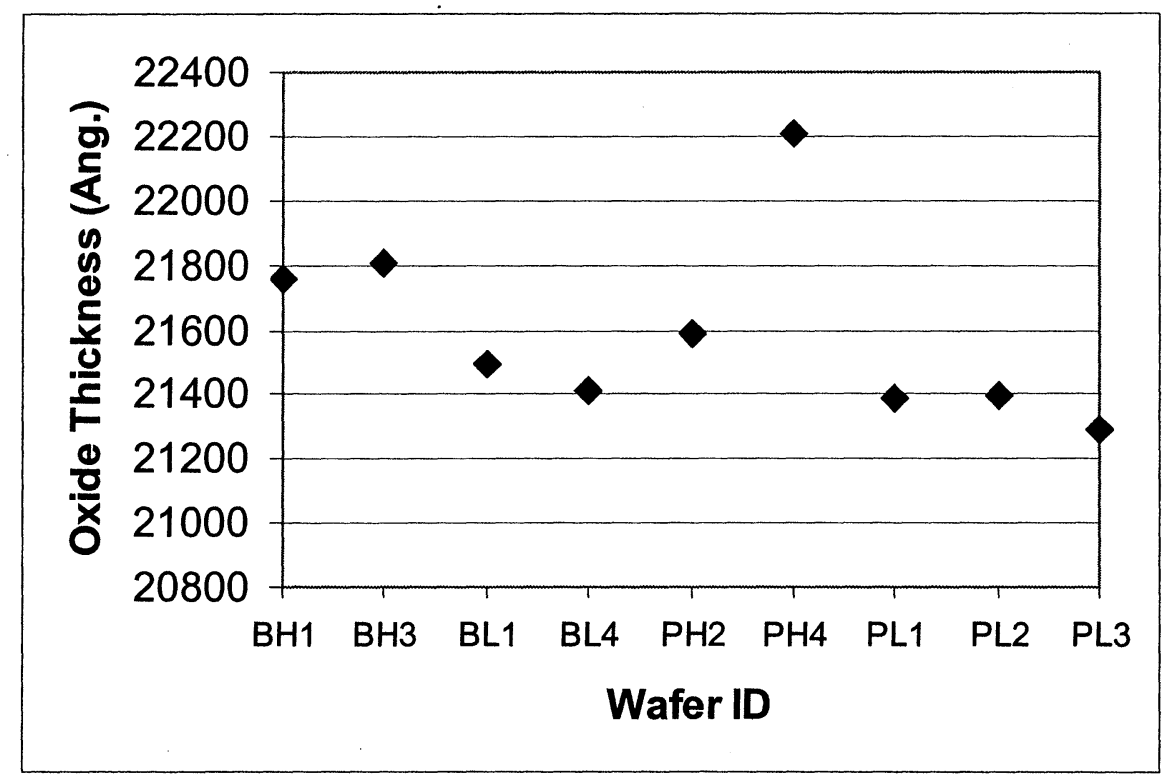

Figure 19. Average thickness of sacrificial oxide layer. 
Table 3. Results of ANOVA Calculations For Oxide Thickness.

\begin{tabular}{|l|c|c|c|l|}
\hline $\begin{array}{l}\text { Source of } \\
\text { Variation }\end{array}$ & Sum of Squares & $\begin{array}{l}\text { Degrees of } \\
\text { Freedom }\end{array}$ & Mean Square & Fo \\
\hline Treatments & 3325617.778 & 8 & 415702.2 & 49.31875 \\
\hline Error & 303440 & 36 & 8428.889 & \\
\hline Total & 3629057.778 & 44 & & \\
\hline
\end{tabular}

A critical value, $F_{c}$ of 3.04 was taken from [16] for $v_{1}=4$ and $v_{2}=40$ degrees of freedom and a $95 \%$ confidence level. As the calculated value of $F_{0}$ is greater than $F_{c}$, it can be concluded that there is a statistical difference in the mean oxide thickness for each of the wafers. Although the statistical analysis predicts a statistical difference in the means, it appears that this difference is due to one "outlier" wafer, PH4, as the difference between all others is only. about $500 \AA$.

\subsubsection{Doping Levels and Dopant Profiles}

Two levels of doping were employed for samples in which the surface polysilicon layer was ion implanted as tabulated in Table 2. The high and low levels were chosen to examine the extremes of any potential doping effects and then compared to a control sample with no ion implantation. As previously mentioned, all wafers were subjected to a $1000{ }^{\circ} \mathrm{C}$ stress relief anneal. This anneal would also serve to activate the dopant and anneal crystal damage caused by the implant. 
To estimate the surface concentrations for each doping dose, the concentration as a function of dose, projected range, and straggle of implant was calculated via Equation 1 [8], which assumes a Gaussian distribution and no channeling effects (amorphous material). While the surfaces implanted were actually single crystal, Equation (1) nevertheless provided an estimate of the surface concentration without too much error as channeling effects were minimized by implanting wafers at an angle.

$$
\begin{aligned}
& \mathrm{N}(\mathrm{x})=\left\{\left(\varphi / \Delta \mathrm{R}_{\mathrm{p}} \sqrt{(2 \mathrm{R}))}\right\} \exp \left\{\left(-\left(\mathrm{x}-\mathrm{R}_{\mathrm{p}}\right)^{2}\right) /\left(2 \Delta \mathrm{R}_{\mathrm{p}}\right)^{2}\right\}\right. \\
& \text { where, } \\
& \mathrm{N}(\mathrm{x})=\text { concentration as a function of distance below surface } \\
& \left.\phi \quad=\text { implant dose (ions } / \mathrm{cm}^{2}\right) \\
& \mathrm{R}_{\mathrm{p}} \quad=\text { projected range }(\mathrm{cm}) \\
& \Delta \mathrm{R}_{\mathrm{p}}=\text { projected straggle }(\mathrm{cm}) \\
& \mathrm{x}=\text { distance below surface }
\end{aligned}
$$

Values for the projected range and straggle were taken from [8] and are tabulated in Table 4.

Table 4. Projected Range, $R_{p}$, and Projected Straggle, $\Delta R_{p}$.

\begin{tabular}{|c|c|c|}
\hline Dopant & $\mathbf{R}_{\mathrm{p}}$ (microns) & $\mathbf{\Delta} \mathbf{R}_{\mathrm{p}}$ (microns) \\
\hline Boron & 0.33 & 0.07 \\
\hline Phosphorus & 0.14 & 0.045 \\
\hline
\end{tabular}


Figure 20 illustrates results of Equation 1 for boron and phosphorus doped at the high doses. As can be seen, the maximum concentration lies at 0.14 microns below the surface for phosphorus and 0.33 microns below for boron. Surface concentrations for the high levels as well as the low levels for each dopant, as determined by Equation 1, are tabulated in Table 5. As can be seen, the high and low concentrations for each dopant are separated by 5 orders of magnitude, allowing for clear distinctions to be made for the differences due to doping level for each dopant.

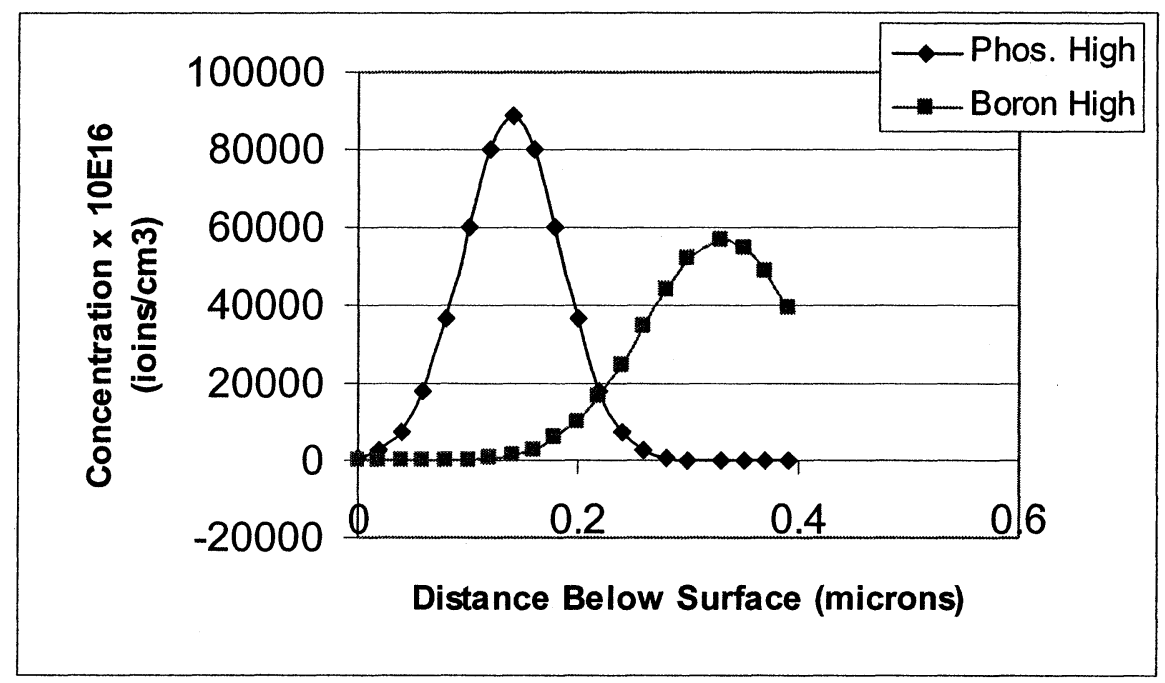

Figure 20. Concentration as a function of distance for high dose implants. 
Table 5. Surface Concentrations for Implanted Wafers.

\begin{tabular}{|c|c|c|}
\hline Dopant & $\begin{array}{l}\text { Surface Concentration: low } \\
\left.\text { level (ions } / \mathrm{cm}^{3}\right)\end{array}$ & $\begin{array}{l}\text { Surface Concentration: } \\
\left.\text { High Level (ions } / \mathrm{cm}^{3}\right)\end{array}$ \\
\hline Boron & $8.5 \times 10^{10}$ & $8.5 \times 10^{15}$ \\
\hline Phosphorus & $7.0 \times 10^{13}$ & $7.0 \times 10^{18}$ \\
\hline
\end{tabular}

Table 5 estimates the as-implanted values of surface concentrations for each dopant. These values would be somewhat altered by the subsequent $1000{ }^{\circ} \mathrm{C}$ stress relief anneal for 3 hours. An estimate of the diffusion length for a given thermal process can be obtained from twice the square root of the diffusion coefficient times the anneal time or, $2 \sqrt{ }(\mathrm{Dt})$. Using this expression for boron, which has a diffusion coefficient of about $2 \mathrm{x}$ $10^{-14} \mathrm{~cm} 2 / \mathrm{s}$, a diffusion length of approximately $0.29 \mu \mathrm{m}$ can be calculated. A similar calculation for phosphorus, with a diffusion coefficient of $1.5 \times 10^{-14}$, yields a value for the diffusion length of $0.25 \mu \mathrm{m}$. As the maximum concentration of boron lies 0.33 microns below the surface and 0.14 microns for phosphorus, this anneal would have the effect of flattening out the curves in Figure 20, leading to higher surface values for each dopant. However, the separation between the two levels would remain relatively constant. The $1000{ }^{\circ} \mathrm{C}$ anneal also has the effect of repairing crystalline damage due to implantation effects. Wolf and Tauber [8] report that even for light elements such as boron, primary crystalline damage can occur, creating dislocations and vacancies. For heavier ions such as phosphorus, $100 \mathrm{keV}$ implants, as was used here, can produce 
substantial damage, leading to the creation of amorphous layers up to 1.5 microns in depth into the lattice [8]. This crystalline damage can be annealed however at temperatures of 900 to $1000{ }^{\circ} \mathrm{C}$ for relatively short anneal times, on the order of 20 minutes [8]. Thus although the high implant conditions used in this investigation for both boron and (especially) phosphorus were expected to cause significant surface damage, the $1000{ }^{\circ} \mathrm{C}$ stress anneal would be sufficient to repair the damage.

\subsection{Results: Release Stiction Analysis}

\subsubsection{Surface Layer Doping Effects}

The effects of ion-implantation doping of the surface polysilicon layer (see Figure 12) are illustrated in Figure 21, which displays the percentage of stuck beams for each doping condition out of a total of 357 beams analyzed for each wafer ( Group 1 in Table 2). As can be seen in Figure 21, the phosphorus high doping condition ( $\mathrm{PH} 4)$ produced a larger percentage of stuck beams on release than any other condition, with nearly $44 \%$ of the beams stuck to the substrate in the first measurement after release. For the control wafer (C8) and the boron high condition (BH3) about $2 \%$ of the beams were stuck to the surface on release, and about $1 \%$ for the phosphorus low condition (PL1). No stuck beams were found for the boron low condition (BL4). A second measurement was performed on the same beam groups after a further drying period of 144 hours, with the results showing a decrease in the number of stuck beams for each condition. The phosphorus high doping condition showed the largest percentage decrease, with $63 \%$ of the beams which were originally stuck releasing. However $15 \%$ of the beams, or about 8 times the number of the second highest condition, remained stuck. 


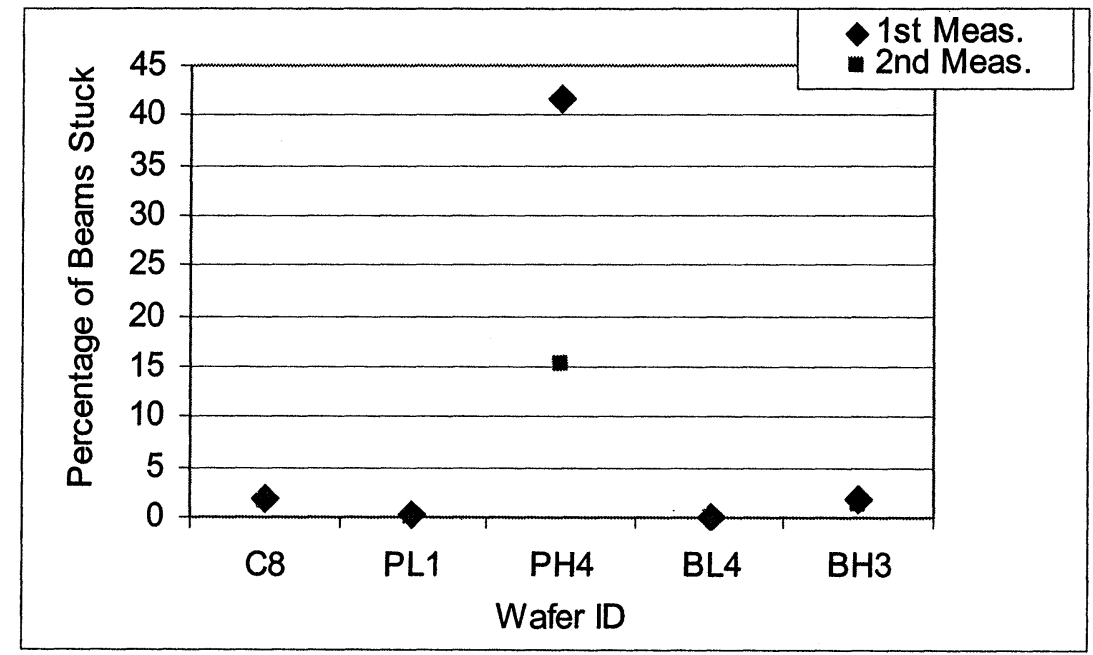

Figure 21. Stiction results for first group of wafers.

A second group of wafers (Group 2 in Table 2) with the identical doping conditions were patterned, released, and dried under similar conditions as the first group. Results for this replicate group are illustrated in Figure 22. As can be seen, the same trend occurs for the second group of wafers with the phosphorus high doping condition (wafer PH2) producing a far larger number of stuck beams than the other conditions. Approximately $70 \%$ of the beams analyzed for the phosphorus high doping condition were stuck on the first measurement, compared to $2.6 \%$ for the phosphorus low condition (PL3), and $4 \%$ for the control wafer (C7). On the second measurement, after an additional 120 hours drying time, all wafers experienced a decrease in the number of stuck beams, however the phosphorus high condition ( $\mathrm{PH} 2)$ had the smallest decrease going from 70 to $62 \%$ of beams stuck. For the phosphorus low condition wafer (PL3), nearly $70 \%$ of the beams originally stuck released on further drying, with the control 
wafer experiencing a decrease of about $26 \%$ on the second measurement (Note: the BL2 wafer from Group 2 was broken during processing).

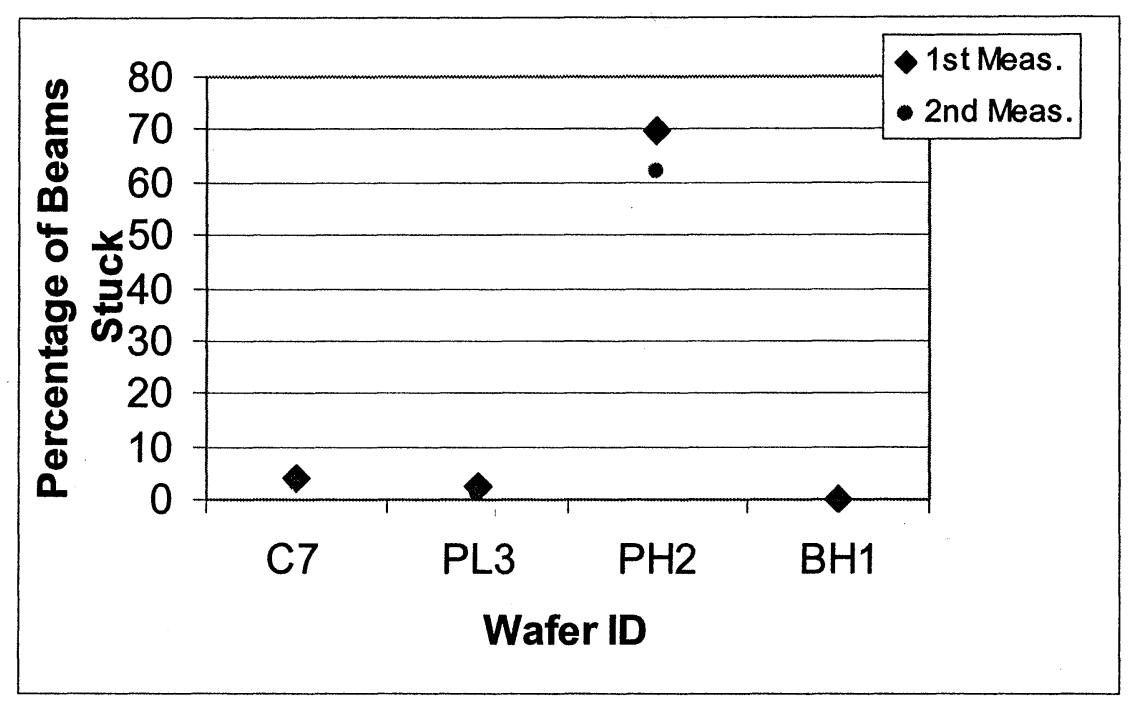

Figure 22. Stiction results for replicate group (Group 2 in Table 2) of wafers.

In comparing the wafers for the high phosphorus doping condition (wafers $\mathrm{PH} 4$ and PH2) between the two replicate groups (1 and 2), they both exhibit a high degree of release stiction compared to the control wafers ( $\mathrm{C} 7$ and $\mathrm{C} 8$ ), however the wafer from Group 2 (PH2) has about a 4-fold increase in the number of stuck beams compared to the wafer from Group 1 (PH4). Wafer PH4 from Group 1 also exhibits a larger change in the number of stuck beams from the first to second measurements, with a $64 \%$ decrease between the two measurements. However, almost no change was observed for Group 2 wafer, $\mathrm{PH} 2$, as is shown in Figures 21 and 22, even though it had a similar drying time to wafer PH4. All wafers, which were allowed to air dry, were exposed to approximately 
the same temperature. However the humidity was not controlled and possible changes in humidity may account for some of the difference between the two. The effects of humidity were investigated by Komvopoulos and Yan [17], who found that high relative humidity (around 90\%) resulted in higher capillary forces at small beam/surface separation distances. Higher humidity also promoted meniscus formation for larger beam/surface separation distances than would occur at lower humidity, meaning that at very high humidity, beams that normally would not experience capillary forces now could.

To examine the significance of the number of beams stuck for each condition between the two replicate groups (Groups 1 and 2 in Table 2), an ANOVA analysis was performed. Results are tabulated in Table 6, with a value for $F_{c}$ of 5.19 taken from [16]. As the critical value is less than the $F_{0}$ value calculated (14.7), it can be concluded that the number of stuck beams between the two groups are statistically different. However, if the phosphorus high condition (wafers $\mathrm{PH} 4$ and $\mathrm{PH} 2$ ) is removed from the analysis, the same calculation yields a value of 1.75 for $F_{o}$ with a corresponding critical value, $F_{c}$, of 6.6. Thus it can be concluded that between the replicate groups (Groups 1 and 2) there is no statistical difference between the number of stuck beams, if the high phosphorus condition is excluded. The difference between the groups can thus be attributed to the high phosphorus doping condition. As was illustrated in Figures 21 and 22, the phosphorus high doping condition (wafers $\mathrm{PH} 4$ and $\mathrm{PH} 2$ ) produced a far greater number of stuck beams than any other condition, with the sample from Group 2, $\mathrm{PH} 2$, producing four times the number of stuck beams than the same wafer from the first group, PH4. As 
previously discussed, this difference may be attributed to possible changes in humidity during the fabrication of the two replicate groups.

Table 6. ANOVA Results for Groups 1 and 2: All wafers.

\begin{tabular}{|l|r|l|l|l|}
\hline Source of Variation & $\begin{array}{l}\text { Sum of Squares } \\
\text { Treatments }\end{array}$ & $\begin{array}{l}\text { Degrees of } \\
\text { Freedom }\end{array}$ & $\begin{array}{l}\text { Mean } \\
\text { Square }\end{array}$ & Fo \\
\hline Error & 4714.8 & 4 & 1178.7 & 14.7 \\
\hline Total & 399.9 & 5 & 80.0 & \\
\hline
\end{tabular}

To examine if there was any difference in the number of beams stuck within a group, a chi-squared test for examining differences among a group of proportions, in this case the proportion of stuck beams for each doping condition, was employed. As it has already been determined that the phosphorus high doping condition has produced a statistically significant greater number of stuck beams than the other doping conditions, this calculation was employed to determine if there was any statistical difference between the number of stuck beams for the remaining doping conditions. The proportions for the Group 1 wafers used in the analysis are tabulated in Table 7. For three degrees of freedom and a $97.5 \%$ confidence level, a value of $\chi^{2}$ (the critical region) of 9.35 is determined [16]. The calculated value of $\chi^{2}$ from the proportion data was determined to be 11.53. As this value is higher than the critical value, it can be 
concluded that there is a statistical difference in the number of stuck beams for the wafers in Table 7. A similar analysis can be done for the Group 2 wafers. Again a statistical difference will be expected for all conditions. Although the proportions used in the analysis predict a statistical difference between the number of stuck beams for each condition in each of the 2 groups, the extremely hydrophobic nature of the wafers (excluding the phosphorus high doping condition) may make this analysis more uncertain. For the first group, the boron low condition produced no stuck beams, while for the replicate group the boron high condition produced no stuck beams. As so few beams were stuck for these conditions, more data would probably need to be taken for each condition to be certain of the results.

Table 7. Proportions of Stuck Beams for Chi-squared Proportion Test: $1^{\text {st }}$ Group.

\begin{tabular}{|l|c|l|l|l|}
\hline & Control (C8) & $\begin{array}{l}\text { Phosphorus Low } \\
\text { (PL1) }\end{array}$ & $\begin{array}{l}\text { Boron Low } \\
\text { (BL4) }\end{array}$ & $\begin{array}{l}\text { Boron High } \\
\text { (BH3) }\end{array}$ \\
\hline Stuck & 7 & 1 & 0 & 7 \\
\hline Not & 371 & 377 & 378 & 371 \\
\hline Ttuck & & & 378 & 378 \\
\hline
\end{tabular}


Table 8. Proportions of Stuck Beams for Chi-squared Proportion Test: $2^{\text {nd }}$ Group.

\begin{tabular}{|l|c|l|l|}
\hline & Control (C7) & $\begin{array}{l}\text { Phosphorus Low } \\
\text { (PL3) }\end{array}$ & $\begin{array}{l}\text { Boron High } \\
\text { (BH1) }\end{array}$ \\
\hline Stuck & 15 & 10 & 378 \\
\hline Not Stuck & 363 & 368 & 378 \\
\hline Total & 378 & 378 & \\
\hline
\end{tabular}

\subsubsection{Surface Layer Doping: Effects of Beam Size on Stiction}

The sizes of beams analyzed ranged from 60 to 400 microns in length, with a constant thickness of two microns for each beam, and a constant beam/substrate separation of two microns. Tas et al., [13] have presented an expression for calculating the critical length of cantilever beams, where the critical length is the minimum length of a beam which can be pulled to the surface by the capillary forces of drying water. Below the critical length, the stiffness, or modulus, of the beam is sufficient to prevent it from being pulled down by the capillary forces. Equation 2 gives the expression derived by Tas [13] for the critical length of cantilever beams,

$$
1_{\mathrm{cr}}=\left[\left(3 \mathrm{Et}^{3} \mathrm{~g}^{2}\right) /\left(16 \gamma_{\mathrm{la}} \cos \theta_{\mathrm{c}}\right)\right]^{1 / 4} \quad \text { Equation (2) }
$$

where: $\quad 1_{\mathrm{cr}}=$ the critical length above which beams will be pulled down

$\mathrm{E}=$ the modulus of polysilicon: $150 \mathrm{GPa}$

$\mathrm{t}=$ the thickness of the polysilicon structural layer: $2 \mu \mathrm{m}$

$\mathrm{g}=$ the gap spacing between the beam and the substrate: $2 \mu \mathrm{m}$ 


$$
\begin{aligned}
\gamma_{\mathrm{a}}= & \text { the surface tension of water: } 76 \mathrm{~mJ} / \mathrm{m}^{2}: \text { un-doped } \mathrm{Si} \\
\theta_{\mathrm{c}}= & \text { contact angle between the water and the silicon surface: } 5^{\circ} \\
& \text { for hydrophilic and } 70^{\circ} \text { for hydrophobic surfaces. }
\end{aligned}
$$

The values of the surface tension of water and the contact angle were taken from [13] for water at $20^{\circ} \mathrm{C}$. Substituting the numerical values into Equation 2, a value for the critical length of 54.7 microns is calculated for the hydrophilic condition and 58.3 microns for the hydrophobic condition. This predicts that beams above these lengths are likely to pulled down to the substrate if there is sufficient water on the wafer surface to create the capillary forces necessary to pull the beam down. Beams analyzed in this experiment ranged from 60 to 400 microns. The above calculation thus predicts that all the beams analyzed in this experiment had the potential to be pulled down to the substrate if sufficient water was present on the wafer surface.

Once a beam is pulled down to the surface of the wafer, it will remain stuck of the surface energy is larger than the restoring force of the beam. Tas [13] has also presented an expression for the critical length of beam to remain stuck to a substrate once pulled down. Equation 3 gives the critical length as a function of beam restoring force (the numerator) and surface adhesion energy (the denominator).

$$
1_{\mathrm{cr}}=\left[\left(3 \mathrm{Et}^{3} \mathrm{~g}^{2}\right) /\left(8 \gamma_{\mathrm{s}}\right)\right]^{1 / 4} \quad \text { Equation (3) }
$$

where: $\quad 1_{\mathrm{cr}}=$ the critical length above which stiction is likely to occur

$$
\mathrm{E}=\text { the modulus of polysilicon: } 150 \mathrm{GPa}
$$


$\mathrm{t}=$ the thickness of the polysilicon structural layer: $2 \mu \mathrm{m}$

$\mathrm{g}=$ the gap spacing between the beam and the substrate: $2 \mu \mathrm{m}$

$\gamma_{\mathrm{s}}=$ the surface adhesion : un-doped $\mathrm{Si}: 100 \mathrm{~mJ} / \mathrm{m}^{2}$

Substituting the values into Equation 3, a value for the critical length which would remain stuck to the substrate if pulled down was determined as 65 microns. This implies that all but the shortest beams had the potential to remain stuck to the substrate if pulled down, assuming an un-doped silicon surface, which was the case for the control condition. This value would go up or down depending on 'how the doping affected the surface energy of the silicon surface.

Figure 23 displays the percentage of stuck beams as a function of beam length for all wafers analyzed in Groups 1 and 2. As can be seen, beams of all sizes do exhibit release stiction, with the greatest number occurring for the 160 micron beam length. Performing a chi-squared proportion test (with a $\alpha$ of 0.025 ) on the data in Figure 23, a value $\chi^{2}$ of 76.3 is determined relative to a $\chi^{2}$ critical of 30.2 [16]. This implies that there is a statistical difference in the proportions of stuck beams as a function of length. As might be expected, the fewest number of stuck beams occur for the shortest beam lengths, as these beams will have a smaller available surface area to contribute to stiction. However, why the largest proportion of stuck beams is at the length of 160 microns is unclear. It might be expected that the highest number of stuck beams would occur for the longest beams. However, if the 4 smallest beams sizes ( 60 through 120 microns) are excluded from the calculation, the proportion test predicts no difference ( $\chi^{2}$ of 22.9 
relative to a $\chi^{2}$ critical of 24.8) in the proportion of stuck beams for the range of 140 to 400 microns. This implies that the shortest beams are indeed the least likely to remain stuck to the substrate due to less surface area.

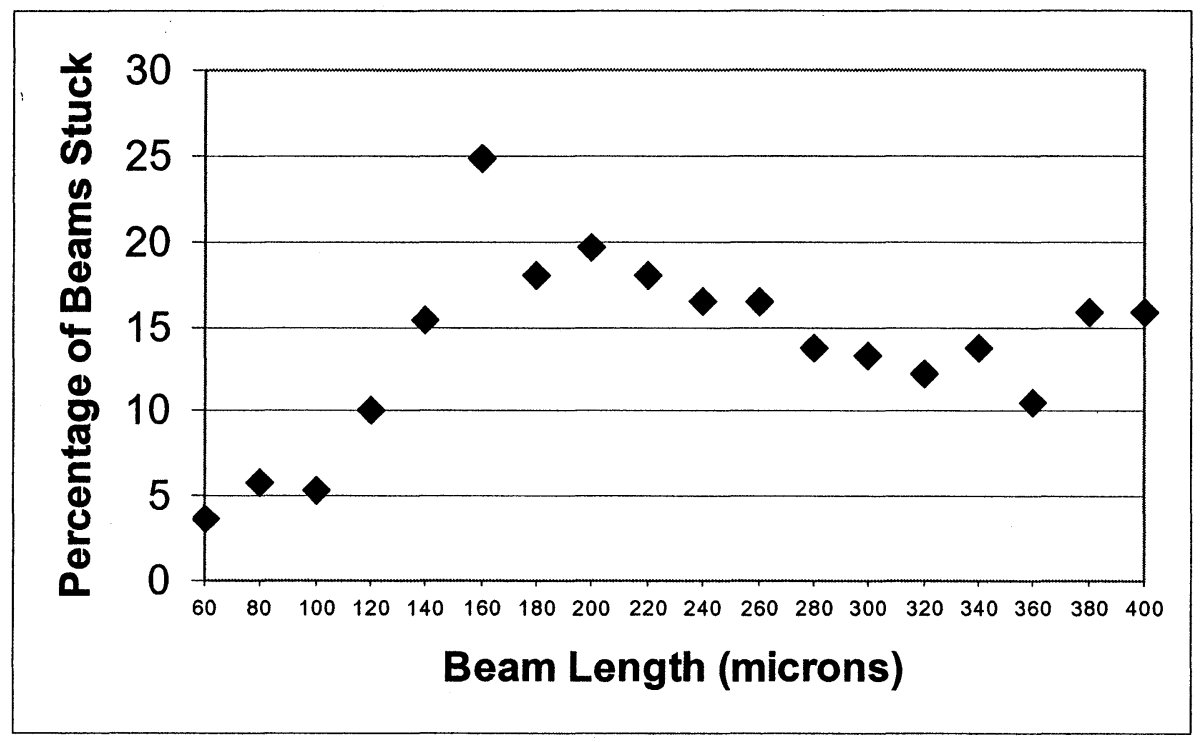

Figure 23. Percentage of stuck beams as a function of length.

\subsubsection{Surface Layer Doping: Shape of Adhered Beam}

All beams which exhibited stiction displayed two distinct shapes. These shapes are commonly referred to as " $\mathrm{S}$ " shape beams, in which a large fraction of the beam is adhered to the substrate and the arc shaped beam, in which only the beam tip is adhered to the substrate. Both of these shapes occurred in this experiment, with a far larger percentage of arc shaped beams being observed. For all wafers analyzed, a total of 443 of 470 stuck beams $(94.3 \%)$ were in the arc shape. An interferometer image of a typical arc shape beam and a corresponding SEM are shown in Figures 24 and 25. An 
interferometer image of a typical "S" shaped beam is shown in Figure 26. The arc shaped beams occurred across the entire range of beam sizes, while the " $\mathrm{S}$ " shape occurred only on the longer

beams.

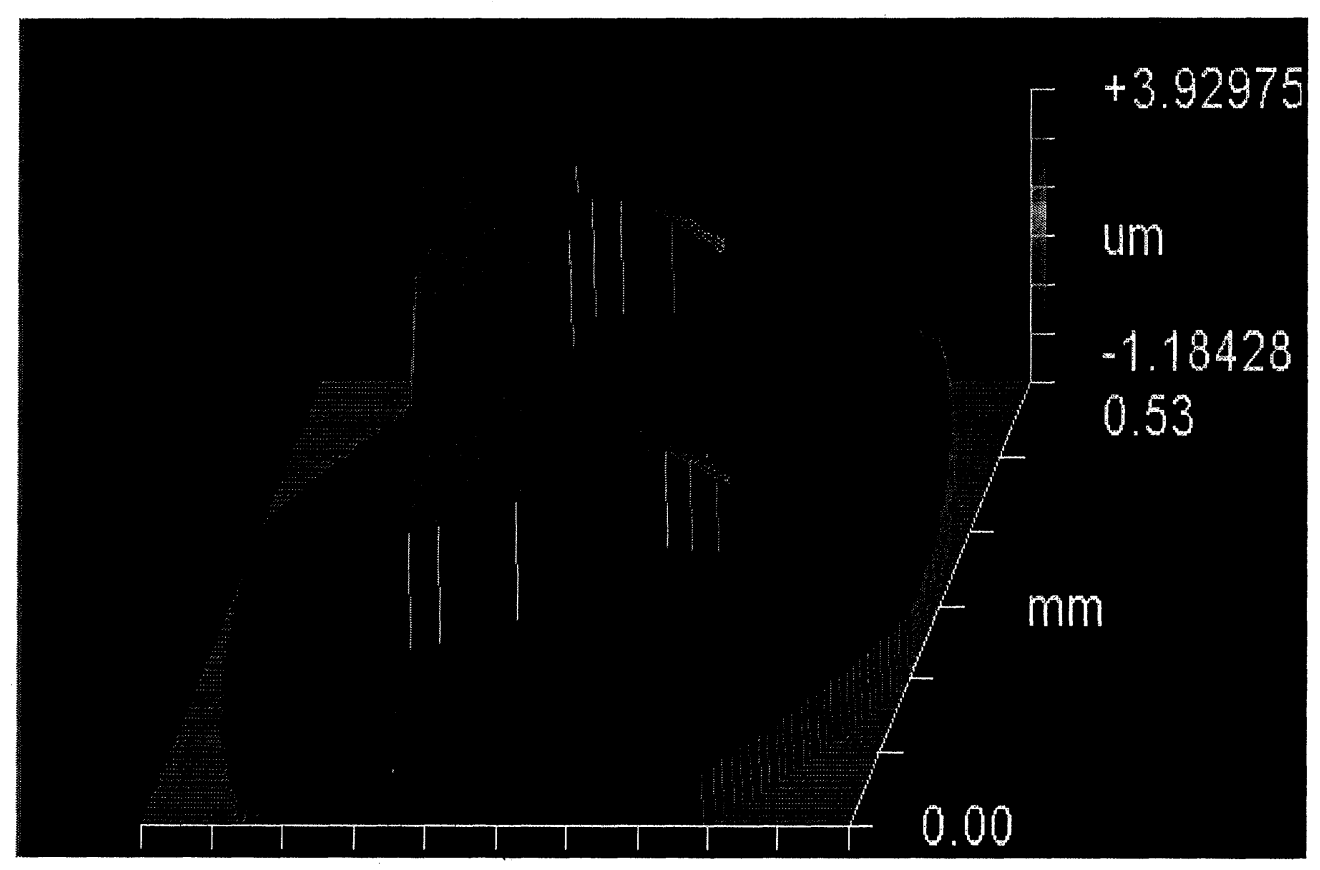

Figure 24. Interferometer image of arc shaped adhered beam. 


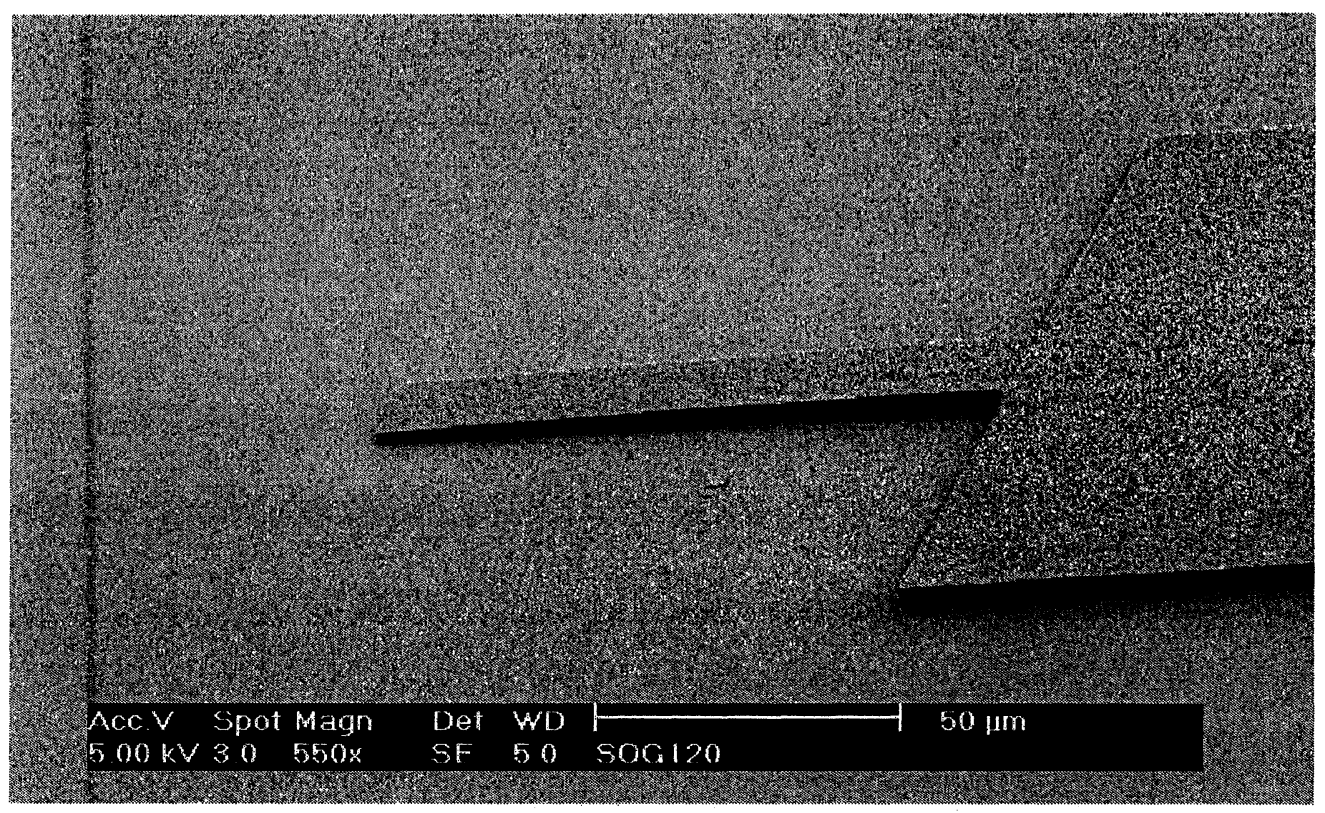

Figure 25. SEM of arc shaped adhered beam.

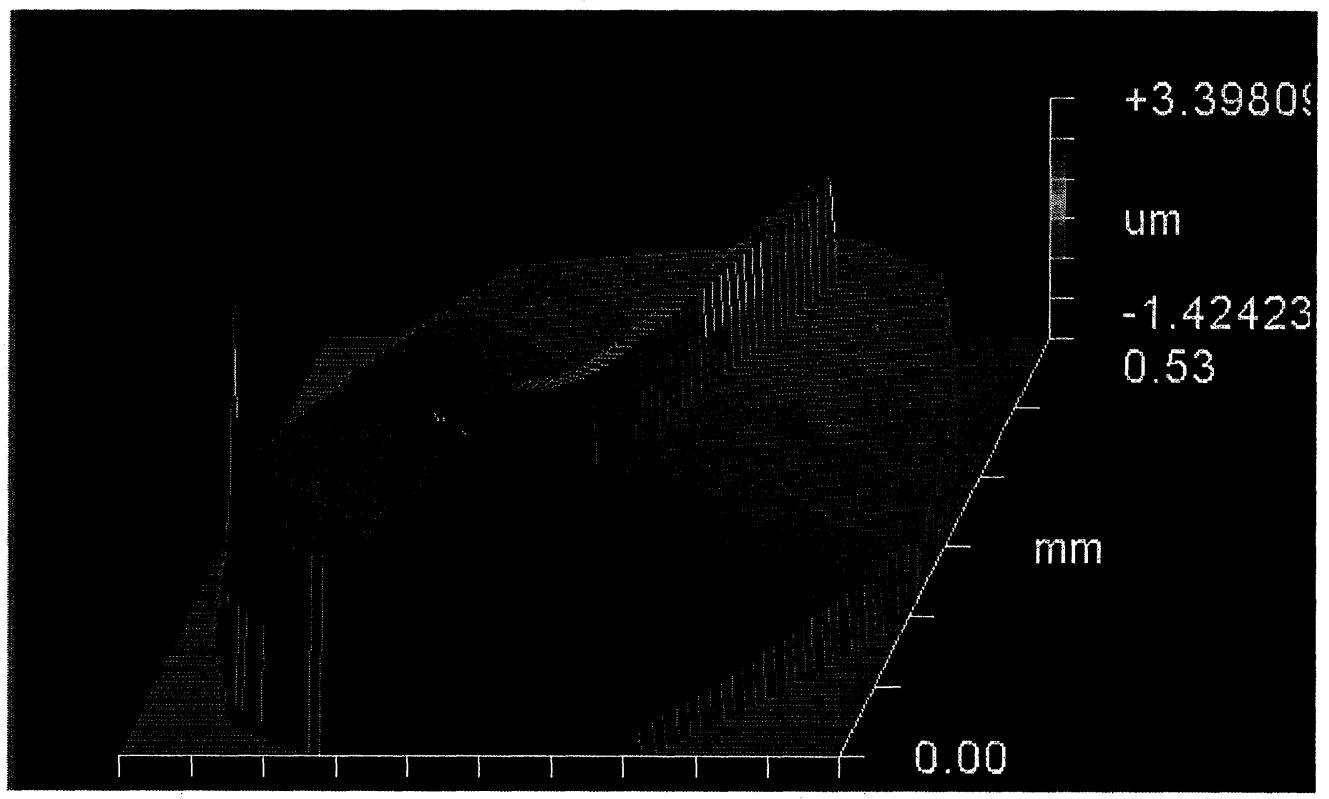

Figure 26. Interferometer image of " $S$ " shaped adhered beam. 
Figure 27 displays the average length of the arc shaped and "S" shaped beams. The average for the arc shape was 265 microns, while the average length of the "S" shaped beam was 387 microns. This result is not surprising as the longer beam has a greater surface area available for contacting the substrate and sticking. While the "S" shaped beams were on average more than a hundred microns longer than the arc shaped beams, several of the arc shaped beams were as long as or longer than the average " $\mathrm{S}$ " shaped. As previously discussed, a number of the beams originally stuck to the substrate released between the first and second measurements. It might be expected that the "S" shaped beams would tend to stay adhered to the substrate longer than the arc shaped beams, as more of the beam is in contact with the surface. However, of the 27 total "S" shaped beams which were originally stuck to the substrate on all wafers, nearly $37 \%$ of those beams released on the second measurement. For the arc shaped beams, only $22 \%$ of the beams released from the substrate. None of the beams were observed to change from " $\mathrm{S}$ " to arc in between measurements, indicating that the arc shaped is probably not an intermediate between the "S" shape and a totally released beam. Which shape a beam assumes thus is probably a function of such factors as the amount of water and thus capillary forces available during drying, smoothness of the beam bottom surface and substrate surface, and the stress state of each particular beam which is typically not constant across a wafer. 


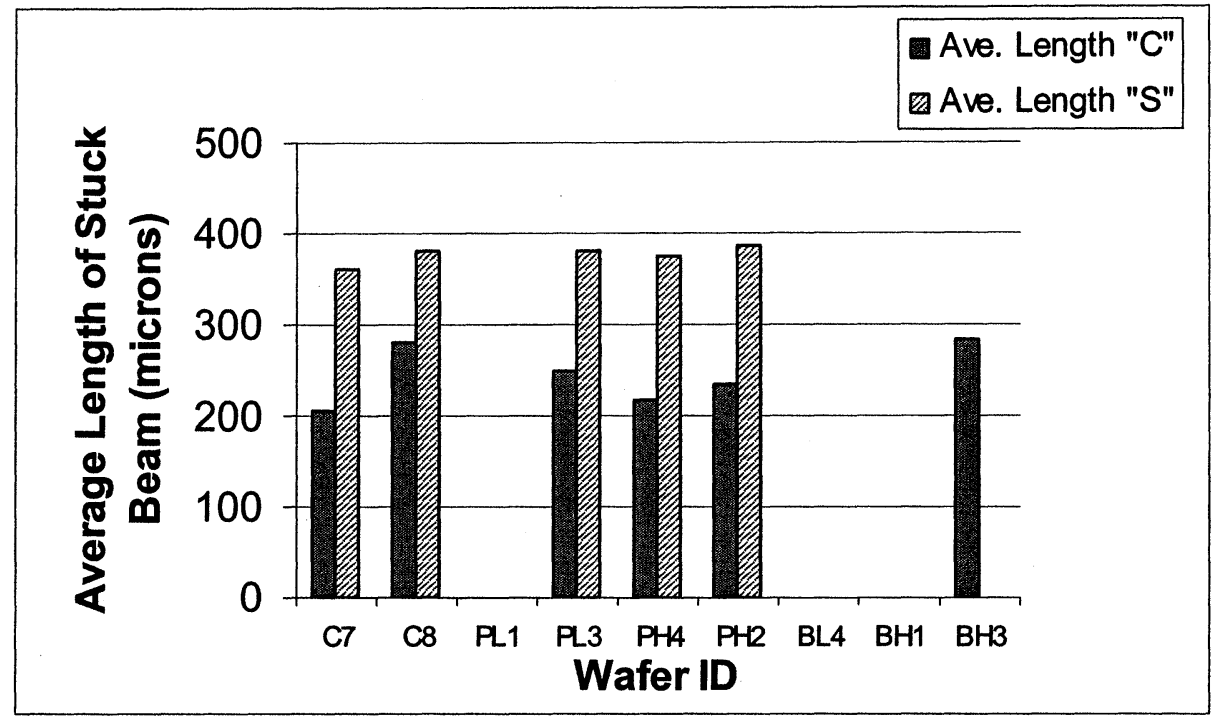

Figure 27. Average lengths of "S" and "arc" shaped beams.

\subsubsection{Structural Poly Layer Doping}

A third group of wafers (Group 3 in Table 2), which had not only ion implantation of the bottom poly layer but also diffusion doping of the top structural poly layer were also analyzed. These wafers were spun with a 0.3 micron thick phospho-silicate glass (spin on glass) and then annealed at $1000^{\circ} \mathrm{C}$ in a nitrogen ambient for 30 minutes to drive phosphorus from the glass layer into the structural poly layer. The doping of the structural layer is common for decreasing the resistivity of the poly layer for devices which will be electrostatically actuated. Wafers in this group included a control wafer with no doping of the bottom poly layer and two wafers in which the bottom poly layer was implanted with either boron or phosphorus at the low doping concentration (see Table 2). 
As previously shown in Figures 21 and 22, wafers with each of these doping conditions in the surface poly layer exhibited a low, and relatively comparable, amount of release stiction. Results for the wafers in which the top structural poly layer was doped are shown in Figure 28. As can be seen in Figure 28, all three wafers exhibited complete release stiction ( $100 \%$ of beams stuck) on the first measurement. On the second measurement, the control and boron wafer had 20 and 17 beams respectively release from the substrate, while the phosphorus wafer showed no decrease.

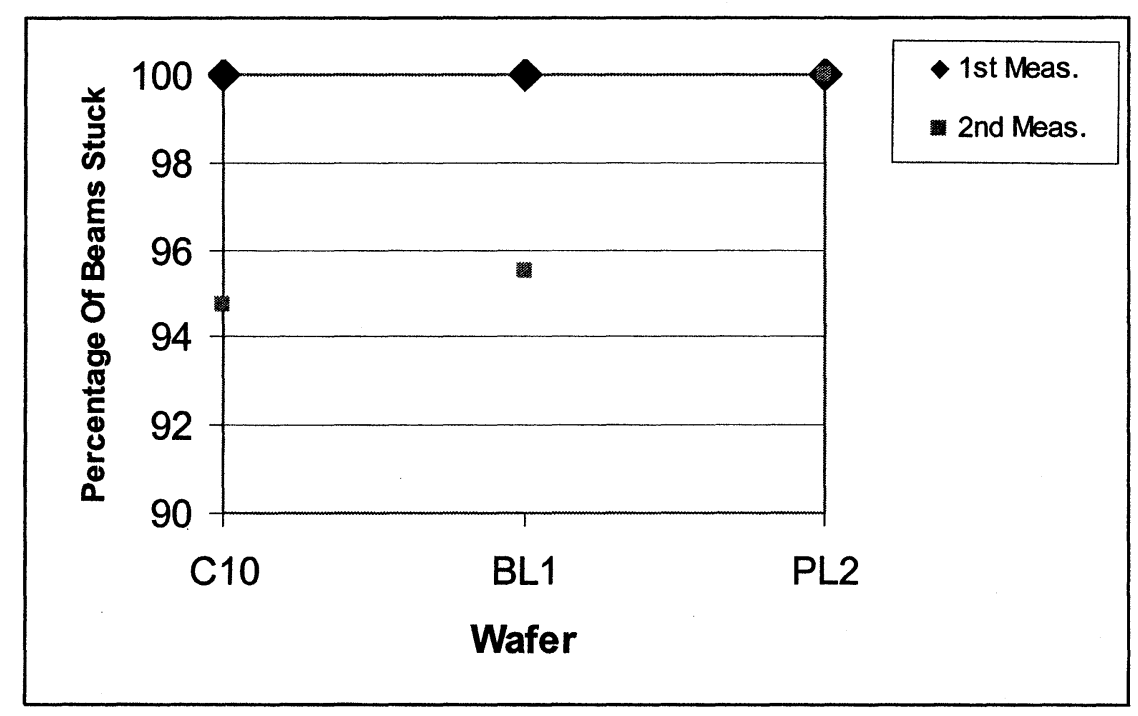

Figure 28. Results for top poly layer doping.

The effects of doping the top poly layer in relation to identical wafers with no doping of the top layer are illustrated in Figure 29. As is illustrated, all samples exhibit significant release stiction when doped with phosphorus (wafers C10, BL1, and PL2) in 
the structural poly layer, compared to identical surface layer doping condition wafers with no doping of the structural poly layer (samples marked with an asterisk). The addition of the phosphorus again appears to alter the silicon surface, changing the surface from hydrophobic to hydrophilic and allowing surface water to pull the beams down to the substrate.

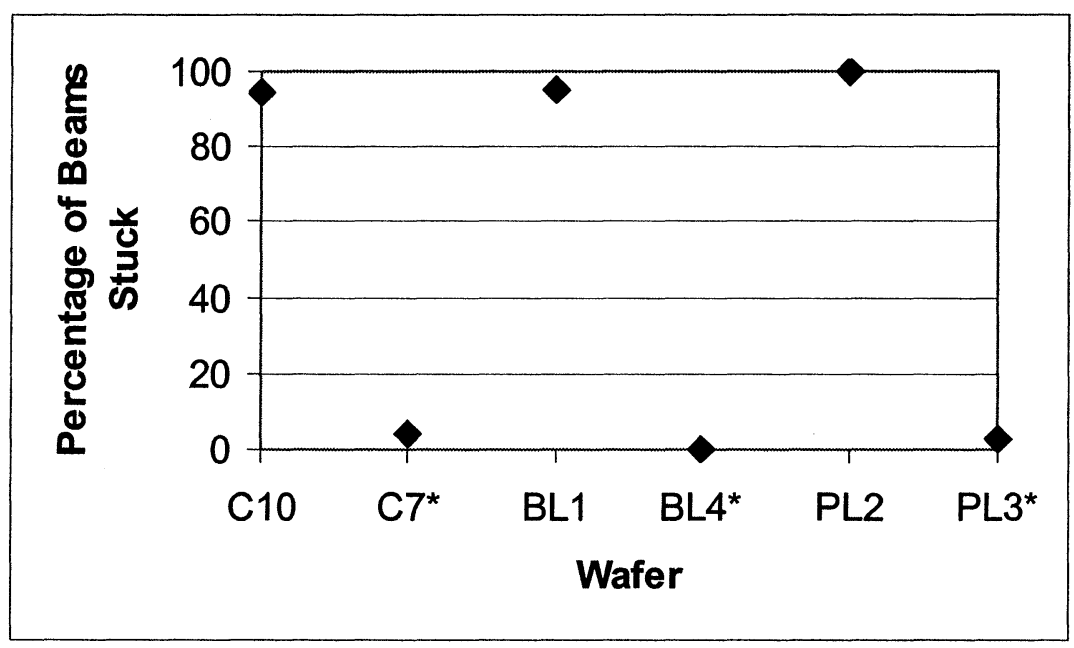

Figure 29. Comparison of structural poly layer doping and surface layer doping.

\subsubsection{Analysis of Results}

The primary goal of this investigation was to determine the effects of doping the surface poly layer and the structural poly layer and observe the effects on the surface energy by examining the amount of release stiction as a function of doping type and level. To insure that the results were related only to the doping conditions, two other factors were also investigated to determine any possible contributing effects. These factors included the sacrificial oxide thickness, which determined the beam/substrate gap 
thickness, and the residual beam stress, which determined beam curvature. As previously shown in Table 3, results of an ANOVA calculation indicated a statistical difference in the oxide thickness for the wafers. However the wafer with the thickest oxide, (PH4) corresponding to the largest beam substrate gap, had the second highest number of stuck beams with 157 measured on the first observation. The sample with the smallest oxide thickness (PL3), and thus smallest gap spacing, had only 10 stuck beams. Thus it can be reasonably concluded that the small differences in oxide thickness ( 0.1 microns maximum) did not significantly contribute to any differences in stiction between wafers.

The results of the beam curvature measurements, as presented in Figure 18 do indicate some differences in beam curvature for several of the wafers. The difference between the height of the beam base and beam end are tabulated in Table 9 for several of the wafers with the largest differences. For all values in Table 9, the residual stress was compressive, meaning the beams had a downward curvature.

Table 9. Beam Base/End Height Difference vs. Number of Stuck Beams.

\begin{tabular}{|c|c|c|}
\hline Wafer ID & $\Delta$ base/end (microns) & Number of Stuck Beams \\
\hline PL3 & 0.93 & 10 \\
\hline BH3 & 0.90 & 7 \\
\hline PH4 & 0.64 & 157 \\
\hline PH2 & 0.2 & 263 \\
\hline
\end{tabular}


As is shown in Table 9, the wafer with the largest number of stuck beams had the smallest amount of curvature, while the two wafers with the largest downward beam curvature had the fewest stuck beams. All remaining wafers had values of curvature of 0.1 microns or less. These results indicate that the small differences in curvature of the beams had no effect on whether a beam would be pulled down to the substrate, and thus on the number of beams stuck for each wafer. It thus can be concluded that structural factors including the sacrificial oxide thickness ( which determines the beam/substrate gap) and the beam curvature had little or no effects on the number of stuck beams, and thus the differences were do solely to the differences in doping.

In examining the effects of doping, it was observed that for wafers with low concentration boron and phosphorus doping of the bottom polysilicon layer, the number of stuck beams is similar, with no wafer exhibiting more than 10 stuck beams. This implies that wafers with the low doping conditions had surface energies similar to the control wafer, which exhibited similar degrees of release stiction. For the wafers with the high boron doping, the number of stuck beams is again similar to the control wafer, however for the high phosphorus doping conditions, wafers from both groups exhibited a significant number of stuck beams compared to the control wafer. Legtenberg [15] reports that silicon surfaces in which the oxide layer is removed with HF and then rinsed with DI water, produces a surface which is very hydrophobic. All wafers in this investigation were released in HF and then rinsed in DI water, and it was experimentally observed that water did not wet the surface of the wafer when removed from the rinse water after release etch, confirming the results of the Legtenberg study [15]. For the 
highly doped phosphorus wafers however, water was observed to wet the surface after DI rinsing, suggesting that the surface of the bottom polysilicon layer, which in this case is heavily doped with phosphorus, has changed from hydrophobic to hydrophilic, allowing more water to remain on the surface after the sacrificial oxide etch. For hydrophilic surfaces, Legtenberg [15] reports that the formation of hydroxyl groups on the surface leads to hydrogen bridging between surfaces, increasing the probability of surfaces sticking when brought into contact. This would suggest that the highly phosphorus doped wafers would exhibit higher degrees of stiction due to their hydrophilic nature, compared to the other conditions which all exhibited hydrophobic behavior. Figures 21 and 22 do indeed show this to be the case.

As Equation 3 predicted that beams of all lengths, except the shortest, used in this investigation (for at least un-doped silicon) had the potential to stick to the surface (a critical length of 65 microns) if brought into contact with it, the question as to why all beams did not stick to the surface upon etch release may be related to the hydrophobic nature of the surface. The highly doped phosphorus condition is the only wafer which exhibited stiction for all lengths of beams. For all other conditions, the data was scattered from the middle length to longer length beams. The Legtenberg study [15] examined both hydrophilic and hydrophobic surfaces, and they observed significant scatter in their detachment length data for the hydrophobic surfaces, with many long beams not sticking and many shorter beams remaining stuck after drying from a DI water rinse. This may be related to the amount of water on the surface of the wafer after etch rinse. As previously mentioned, all wafers with the exception of the highly doped phosphorus wafers repelled 
water when removed from the post-etch rinse. For release stiction to occur, beams must be pulled down to the surface of the wafer by the capillary forces of drying water. There may not have been enough water available on the surface of the hydrophobic wafers to pull the beams to the substrate.

The effects of drying time on the number of beams sticking to the wafer are shown in Figures 21 and 22 with less beams remaining stuck on the second observations for most cases. It is unclear as to why beams would release after several days after initially being pulled to the surface. A potential explanation may be related to the surface roughness of the bottom poly layer. Legtenberg (15) surmised that surface effects, such as contamination and especially surface roughness, which affects the contact area, may be the reason for the discrepancy in the number and lengths of beams which stick to the wafers. The prediction by Equation 3 that beams (in this study) of a certain length would stick is based on the surface energy of a single-crystal silicon surface, which is expected to be very smooth. The surface used in these experiments was not the wafer surface, but a CVD polysilicon layer. It was observed during CVD operations that as the poly layer became thicker, the surface became noticeably (visually) rougher. As surfaces become rougher, there is less contact area, effectively decreasing the surface energy of the surface. For the hydrophilic wafers, which had many beams pulled to the surface presumably due to the excess of water on the substrate, the effects of the surface roughness may not have been immediately apparent. However, as the water completely dried, the surface roughness may have been such that the some of the beams were no longer favored to stick to the surface. For the hydrophobic wafers, which may not have 
had many beams pulled to the surface to begin with, the beams that did initially stick also showed a decrease in the number of them sticking on the second observation. In order to accurately predict which length of beam would stick by Equation 2, the surface energy (especially for a CVD deposited surface) would most likely need to be experimentally determined for that particular surface.

Surface roughness effects would likely need to be considered in greater detail to fully examine its effects on stiction. Atomic Force Microscopy (AFM) would allow the characterization of the surface to which the beams would be potentially in contact with. Ideally surface roughness must be minimized to insure that stiction effects were entirely related to doping conditions.

The wafers with the phosphorus doping of the top structural layer confirm the result that high concentrations of phosphorus produce large increases in release stiction. As Figure 29 illustrates, wafers with conditions that produced very little release stiction upon release, showed large increases in stiction when doped with phosphorus from the top layer. These results along with the results from the samples with bottom layer doping only ( in which wafers with the high phosphorus doping condition displayed far greater release stiction), imply that it is indeed the phosphorus doping at high levels that cause the large increase in release stiction. Replacing silicon sites with phosphorus appears to change the surface from hydrophobic to hydrophilic. The higher valence of phosphorus, compared to silicon, coupled with the polar nature of the water molecule may make it more likely that water would be attracted to the phosphorus doped surface. 
One of the goals of this study was to calculate the surface energy of the different conditions. Several studies have used Equation 3, or a similar form $[14,15]$, to calculate the surface energy of a surface, by using the shortest beam stuck and then back calculating the adhesion energy. As there was a lot of scatter in the data for all wafers in this investigation, it was not possible to calculate adhesion energies for the different conditions. As it appears that the release stiction was strongly dependant on the nature of the surface (hydrophobic or hydrophilic). A different technique which would not depend on these effects would be to examine the effects of in-use stiction. This could be accomplished by electro-statically actuating beams on completely dried wafers and then observing the minimum length of beam which remained stuck. It was observed during SEM analysis of test wafers with no doping, that beams (in the 300 micron range; shorter beams were not examined) remained attached to the surface after being actuated by the electron beam of the SEM. This represented only a small, statistically insignificant amount of data, so no real conclusions can be drawn from it, but it shows the potential for more accurately determining the true critical length of a beam, and thus being able to accurately calculate the surface energy. 


\section{CHAPTER 5}

\section{CONCLUSIONS}

The results of this investigation clearly demonstrate that doping of either the surface polysilicon layer or the structural polysilicon layer with phosphorus produces a large increase in release stiction. Wafers doped with low doses of boron or phosphorus $\left(1 \times 10^{11}\right.$ atoms $\left./ \mathrm{cm}^{2}\right)$, as well as control wafers with no doping, produced similar low levels of release stiction. Wafers doped with high doses of phosphorus $\left(1 \times 10^{16}\right.$ atoms $/ \mathrm{cm}^{2}$ ) however produced a greater than ten-fold increase in the number of beams

stuck. A similar high dose $\left(1 \times 10^{16}\right.$ atoms $\left./ \mathrm{cm}^{2}\right)$ of boron produced results no different from the low concentrations or the control wafer.

This implies that high concentrations of phosphorus can affect the surface of silicon, changing it from hydrophobic to hydrophilic. The levels of phosphorus that resulted in the increase in release stiction are on the order of doping levels used to dope polysilicon for devices that are to be electro-statically actuated, lowering the sheet resistance from virtually infinite to around $60 \mathrm{ohm}$. Similar high concentrations of boron give nearly the same resistance, yet produce no increase in release stiction.

Although it was experimentally observed that the high phosphorus condition changed the surface from hydrophobic to hydrophilic (by the behavior of water on the surface) surface energies were not measured or calculated. A wider range (lower lengths and possibly greater thicknesses) of beams would be necessary to utilize Equation 3 to back calculate the surface energy from the smallest beam stuck for each condition. Also 
since very few of the beams stuck for the conditions other than the high phosphorus doped condition, stiction data from an alternate experimental technique, such as electrostatic actuation, would yield more complete results. Future work that could answer this question would include making beams with a wider range of sizes and electrostatically actuating the beams to observe differences in stiction. Beams could be released and dried via a technique such as supercritical drying, to avoid release stiction, and then actuated to determine in-use stiction. The results of this study, which indicate that the surface energy has possibly been increased by doping with phosphorus, would suggest the possibility that in-use stiction would be increased as well. This would allow a determination of any possible correlations between release stiction and in-use stiction.

Results also indicate a drying time effect, for examining release stiction. Based on the literature, samples were initially allowed to air dry for 48 hours before examination. Further measurements however, at times of up to 192 hours showed decreases in the number of stuck beams for all sample types. Further experimentation would be needed to determine optimum drying times and techniques, due to possible uncontrollable influences such as humidity, to insure accurate results. 


\section{References}

1. D. Bishop, P. Gammel and C. Giles, "The Little Machines that are Making it Big," Physics Today, 38 (2001).

2. J. Benoit, "Micro and Nanotechnologies: A Challenge on the Way Forward to New Markets”, Materials Science and Engineering B51, 254, (1998).

3. Sandia National Laboratories Website, www.sandia.gov/mstc/index.html.

4. D. Bishop, Silicon Micromachines for Lightwave Networks, Short Course- OFC 2001, Optical Society of America, 1-100, (2001).

5. B. Bhushan and X. Li, "Micromechanical and Tribological Characterization of Doped Single Crystal Silicon and Polysilicon Films for Microelectromechanical Systems and Devices," The Journal of Materials Research, 12 (1), 54, (1997).

6. C.H. Mastrangelo, and C.H. Hsu, "A Simple Experimental Technique for the Measurement of the Work of Adhesion of Microstructures," Micro-Sensors \& Actuators Department, Ford Motor Company, (1992).

7. M.P. De Boer, J.A. Knapp, T.A. Michalske, U. Srinivasan, \& R. Maboudian, “Adhesion Hysteresis of Silane Coated Microcantilevers," Acta Materialia, 48, 4531, (2000).

8. S. Wolf, and R. Tauber, Silicon Processing for the VLSI Era, $2^{\text {nd }}$. Edition (Lattice Press, 2000), pp. 180, 324.

9. R. Hegde, W. Paulson and P. Tobin, "Surface Topography of Phosphorus Doped Polysilicon," Journal of Vacuum Science and Technology B, 13, 1434, (1995).

10. D. Maier-Schneider, A. Koprululu, S. Ballhausen Holm and E. Obermeier, "Elastic Properties and Microstructure of LPCVD Polysilicon Films, " Journal of Micromechanics and Microengineering, 6, 436, (1996).

11. L. Elbrecht, R. Catanescu, J. Zacheja and J. Binder, "Highly Phosphorus Doped Polysilicon Films with Low Tensile Stress for Surface Micromachining Using POCl3 Diffusion Doping," Sensors and Actuators A 61, 374, (1997).

12. M. Furtsch, M. Offenberg, A. Vila, A. Cornet and J.R. Morante, "Texture and Stress Profile in Thick Polysilicon Films Suitable for Fabrication of Microstructures, " Thin Solid Films, 296, 177, (1997). 
13. N. Tas, T. Sonnenberg, H. Jansen, R. Legtenberg, \& M. Elwenspoek, "Stiction in Surface Micromachining", Journal of Micromechanics and Microengineering, 6, 385, (1996).

14. M.P. deBoer, and T.A. Michalske, "Accurate Method for Determining Adhesion of Cantilever Beams," Journal of Applied Physics, 86 (2), 817, (1999).

15. R. Legtenberg, H. Tilmans, J. Elders and M. Elwenspoek, "Stiction of surface micromachined Structures After Rinsing and Drying: Model and Investigation of Adhesion Mechanisms," Sensors and Actuators A, 43, 230, (1994).

16. R.E. Walpole, R.H. Myers, S.L. Myers and K. Ye, Probability and Statistics for Engineers and Scientists, $7^{\text {th }}$ edition, (Prentice Hall,Upper Saddle River, New Jersey 2002), pp. 330-340.

17. K. Komvopoulos and W. Yan, "A Fractal Analysis of Stiction in Microelectromechanical Systems," Journal of Tribology, 119, 391, (1997). 


\section{APPENDIX Equipment Operating Conditions}

\section{A.1 Polysilicon Reactor Conditions}

Reactor Type: Tylan Horizontal Tube Furnace: 4"

SiH4 Flow Rate: $30 \mathrm{sccm}$

H2 Flow Rate: 10 sccm

Tube Pressure:500 mT

Tube Temperature: $620^{\circ} \mathrm{C}$

\section{A.2 Low Temperature Oxide (LTO) Reactor Conditions}

Reactor Type: Tylan Horizontal Tube Furnace: 4"

SiH4 Flow Rate: 40 sccm

O2 Flow Rate: $20 \mathrm{sccm}$

Tube Pressure: $500 \mathrm{mT}$

Tube Temperature: $400{ }^{\circ} \mathrm{C}$

\section{A.3 Reactive Ion Etch Reactor Conditions}

Reactor Type: Drytek Plasma Etch

CH4 Flow Rate: 51 sccm

SF6 Flow Rate: $117 \mathrm{sccm}$

Chamber Pressure: 150 mTorr

RF Power: 400 Watts 